Vítor de Góes Lima Dantas

\title{
ESTUDOS MOLECULARES NA PERDA AUDITIVA DE HERANÇA AUTOSSÔMICA DOMINANTE
}

\author{
Tese apresentada ao Instituto de Biociências \\ da Universidade de São Paulo, para obtenção \\ do Título de Doutor em Ciências, na Área de \\ Biologia/Genética. \\ Orientadora: Profa. Dra. Regina Célia \\ Mingroni Netto
}

São Paulo 
A surdez pode ser causada por fatores ambientais, genéticos ou ambos. Do ponto de vista genético, a surdez é extremamente heterogênea, pois é condicionada por mutações em diversos genes localizados em diferentes cromossomos, podendo exibir mecanismos de herança diversos. O objetivo desse estudo foi identificar novos genes e mutações relacionados à perda auditiva de herança autossômica dominante. Foram estudadas molecularmente cinco famílias. A família 1 foi averiguada na cidade de Maringá-PR. Apresenta 20 indivíduos afetados pela síndrome Oto-branquial (BOS). Estudos de mapeamento gênico com arrays de SNPs mostraram um Lod Score sugestivo de ligação para uma região do cromossomo 8, onde está localizado o gene EYA1, já relacionado à síndrome. O sequenciamento dos exons do gene não revelou mutação. No entanto, estudos de array-CGH e de PCR em tempo real permitiram detectar uma duplicação de aproximadamente $86 \mathrm{~kb}$ no gene EYAl em 11 dos 12 indivíduos afetados testados da família, ausente nos indivíduos fenotipicamente normais. Portanto, concluímos que a síndrome nessa família é decorrente dessa duplicação, nunca antes descrita em casos de BOS. A família 2 foi averiguada na cidade de São Miguel-RN, com 16 indivíduos afetados por perda auditiva de herança autossômica dominante não sindrômica. Estudos de mapeamento gênico com marcadores moleculares do tipo microssatélites e cálculos de Lod Score indicaram uma região no cromossomo 3 como candidata a conter o gene responsável pelo fenótipo na família. Estudos de sequenciamento massivo em paralelo da amostra de um indivíduo afetado apontaram três variantes missense em heterozigose como sendo as mais prováveis causas do fenótipo, mas duas delas foram excluídas com base em estudos de segregação. A terceira variante foi triada em uma coleção de 47 amostras de probandos de famílias com surdez autossômica dominante, mas não foi encontrada. Há estudos em andamento buscando confirmar seu papel na surdez hereditária. A família 3 foi averiguada na cidade de São Paulo-SP e apresenta 15 indivíduos afetados por perda auditiva de herança autossômica dominante não sindrômica. Estudos de mapeamento gênico com o uso de arrays de SNPs e cálculos de Lod Score mapearam uma região no cromossomo 20 como candidata a conter o gene responsável pelo fenótipo. Estudos de sequenciamento massivo em paralelo de amostras de dois indivíduos afetados apontaram três variantes missense em heterozigose como as mais prováveis causas do quadro. Estudos de segregação excluíram duas das variantes e a terceira variante foi triada na coleção de 47 amostras de probandos de famílias com surdez de herança dominante, mas não foi encontrada. Outros estudos estão em andamento para verificar seu papel na surdez. A família 4 foi averiguada na cidade de Porto Alegre-RS e apresenta 11 indivíduos afetados por perda auditiva de herança autossômica dominante não sindrômica. Estudos de mapeamento genético com o uso 
de arrays de SNPs e de cálculo de Lod Score mapearam duas regiões, nos cromossomos 14 e 22, como candidatas a conter o gene responsável. Estudos de sequenciamento massivo em paralelo em amostras de três indivíduos afetados apontaram 3 variantes missense em heterozigose nas regiões mapeadas (duas no cromossomo 14 e uma no cromossomo 22). Observamos que somente a variante rs80338828 no gene $M Y H 9$, no cromossomo 22, segrega com o fenótipo. Essa variante já foi previamente relacionada à perda auditiva de herança autossômica dominante e provavelmente explica a perda auditiva na família. A família 5 foi averiguada na cidade de São Paulo-SP e apresenta 30 indivíduos afetados por perda auditiva de herança autossômica dominante e não sindrômica. Estudos de ligação com arrays de SNPs e cálculos de Lod Score não apontaram a região candidata devido a limitações computacionais e à estrutura da genealogia. Estudos de sequenciamento massivo em paralelo de amostras de quatro indivíduos afetados apontaram 13 variantes presentes nos quatro, em heterozigose. Foram selecionadas para estudo duas das variantes, uma no gene $M Y O 3 A$, por se tratar de um gene já relacionado à perda auditiva e uma no gene $L O N P 2$, por se tratar de uma mutação de códon de parada prematuro. Estudos de segregação mostraram que a variante no gene $L O N P 2$ não segrega com o fenótipo na família e que a variante no gene MYO3A parece segregar com o fenótipo, exceto por sua ausência em um indivíduo afetado e sua presença em sete indivíduos aparentemente normais, que poderiam ser não-penetrantes. Mutações no gene MYO3A já foram relacionadas previamente à perda auditiva de herança autossômica recessiva, mas chama a atenção o fato do padrão de herança nessa família ser o dominante. Mais estudos são necessários para confirmar o papel dessa e de outras variantes no fenótipo da família. Portanto, o estudo molecular das cinco famílias revelou dois possíveis novos genes de surdez, um novo mecanismo mutacional na síndrome BOS, mutação em gene já conhecido e hipótese de novo mecanismo de herança para mutação no gene MYO3A. 


\section{Abstract}

Deafness can be caused by environmental factors, genetic factors or both. Genetic deafness is highly heterogeneous, because it is caused by mutations in many genes located in different chromosomes and can be explained by different inheritance patterns. The aim of this study was to identify new genes and search for new mutations related to autosomal dominant hearing loss. Five families were selected for molecular studies. Family 1 was ascertained in Maringá-PR. It includes 20 individuals affected by Branchio-oto syndrome (BOS). Genomic scanning with SNP arrays showed suggestive Lod scores on a region at chromosome 8, where the EYA1 gene is located, already known to be related to this syndrome. Sequencing of all exons of the gene did not reveal the mutation. However, array-CGH and real time PCR studies detected a duplication of $86 \mathrm{~kb}$ on EYAl gene, in 11 of the 12 affected individuals tested, and it was absent in the unaffected individuals. Our findings implicate this EYAl duplication in the BOS1 phenotype observed in the pedigree. Large duplications in EYA1 gene were not reported before. Family 2 was ascertained at São Miguel-RN, with 16 individuals affected by non syndromic autosomal dominant hearing loss. Genomic scanning with microsatellites and Lod score calculations mapped a region at chromosome 3 as candidate to contain the gene responsible for the phenotype in the family. Massive Parallel Sequencing of a sample from one affected individual indicated 3 missense variants in heterozygosis that could explain the phenotype. Two variants were excluded after segregation studies. The third variant was screened in a cohort of 47 probands from families with individuals affected by autosomal dominant hearing loss and it was not detected. Further studies are needed to confirm its role in hearing loss. Family 3 was ascertained in São Paulo-SP and presents 15 individuals affected by non syndromic autosomal dominant hearing loss. Genomic scanning with SNP arrays and Lod score calculations suggested a region at chromosome 20 as the candidate to contain the gene that causes the phenotype. Massive Parallel Sequencing with samples from two affected individuals suggested 3 missense variants in heterozygosis that could explain the phenotype. Two variants were excluded after segregation studies and one variation was selected as the best candidate to explain the phenotype. We searched for this variant in a cohort of 47 probands from families with individuals affected by autosomal dominant hearing loss and it was not detected. Other studies are being conducted to confirm the role of this variation in deafness. Family 4 was ascertained at Porto Alegre-RS and presents 11 individuals affected by non syndromic autosomal dominant hearing loss. Genomic scanning with SNP arrays and Lod score calculations indicated two regions, at chromosomes 14 and 22, as the best candidates to contain the hearing loss gene. Massive Parallel Sequencing studies with samples from 3 affected individuals indicated 3 missense variants in heterozygosis 
(two variants at chromosome 14 and one at chromosome 22). We observed that only the variant rs80338828, in MYH9 gene, in chromosome 22, segregates with the phenotype. This variant was previously related to autosomal dominant hearing loss and probably explains the phenotype observed in this family. Family 5 was ascertained at São Paulo-SP and presents 30 individuals affected by non syndromic autosomal dominant hearing loss. Genomic scanning with SNP arrays and Lod score calculations did not indicate candidate regions due to computer limitations. Massive Parallel Sequence studies with samples from four affected individuals suggested 13 candidate variants, in heterozygosis. Two variants were selected for further studies: one in $M Y O 3 A$, previously related to hearing loss, and one in $L O N P 2$ gene, a nonsense mutation. Segregation studies showed the LONP2 variant did not segregate with the phenotype and $M Y O 3 A$ variant seems to segregate with the phenotype, except for its absence in one affected individual and its presence in seven unaffected ones, who could be nonpenetrants. Mutations in MYO3A were previously related to autosomal recessive hearing loss, but the family described here presents autosomal dominant pattern of inheritance. More studies are needed to explain the role of this variant in the phenotype. Thus, the molecular study of five pedigrees revealed two novel candidate genes for deafness, one novel mutation mechanism in BOS, a mutation in one previously known gene and the possibility of a novel inheritance mechanism for a MYO3A mutation. 


\section{REVISÃO BIBLIOGRÁFICA}

\subsection{Audição e Perda auditiva.}

As informações a seguir foram obtidas principalmente dos artigos de revisão de Carlson (1998), Willems (2000) e Pujol e col. (2002).

A audição é caracterizada pela capacidade do ser humano receber, escutar e interpretar as ondas sonoras produzidas no meio em que vive. Ela é o meio pelo qual o indivíduo tem contato com os sons e, portanto, é de suma importância para que possa adquirir e aprimorar as habilidades de linguagem.

O deficiente auditivo pode não conseguir perceber esses sons, a depender do grau e a idade do início da deficiência. Em consequência, há um comprometimento de várias capacidades que dependem do correto funcionamento da audição. Além do mais, a perda auditiva pode isolar o indivíduo do mundo, o que pode acarretar vários distúrbios psicológicos e de interação. Portanto, a deteç̧ão da deficiência e o correto diagnóstico nos primeiros meses de vida são importantes para que se tomem as medidas adequadas para minimizar os danos que a deficiência possa vir a causar no indivíduo.

Nesse estudo, o termo surdez será comumente utilizado para definir qualquer tipo de perda auditiva independente do tipo ou grau de comprometimento. Os termos surdez, perda auditiva e deficiência auditiva serão considerados sinônimos nesse estudo, embora em textos de audiologia seja feita a distinção entre os termos surdez e os demais, o termo surdez sendo reservado para perdas graves ou profundas.

A perda auditiva pode ser causada por uma enorme variedade de fatores, sendo, portanto uma característica multifatorial. Suas causas podem ser tanto genéticas quanto ambientais ou uma combinação de ambos os fatores. Em países pouco desenvolvidos, as doenças infecciosas são as principais responsáveis pela alta incidência da perda auditiva. Entretanto, em países desenvolvidos, a principal causa de perda auditiva são as causas genéticas, uma vez que o sistema de saúde provê melhor acesso a cuidados com a saúde materna e infantil. Portanto, à medida que o sistema de saúde melhora, os casos de perda auditiva decorrentes de causas infecciosas tendem a diminuir e, com isso, os casos decorrentes de deficiência hereditária se tornam proporcionalmente mais frequentes (Grundfast, Atwoo e Choung, 1999). Além das 
doenças infecciosas, temos também como causas ambientais as exposições a drogas ototóxicas, os traumas físicos e acústicos.

De acordo com a organização mundial de saúde, em 2013, cerca de 360 milhões de pessoas sofrem de perda auditiva dos tipos moderada a grave, sendo que $80 \%$ dessas pessoas estão em países em desenvolvimento ou subdesenvolvidos. No Brasil, segundo o censo IBGE/2000, cerca de $30 \%$ da população sofre de perda auditiva de algum tipo ou grau, o que corresponde a aproximadamente 5,7 milhões de deficientes.

É estimado que, em países desenvolvidos, cerca de um em cada mil nascimentos sejam de deficientes auditivos com grau de grave a profundo. No Brasil essa frequência pode atingir três ou quatro em cada mil nascimentos (Braga e col., 1999; Piatto e Maniglia, 2001), devido a causas ambientais. Em relação aos casos genéticos, o padrão de herança mais frequentemente encontrado é o padrão de herança recessivo, especialmente entre os pré-linguais. No que se refere à perda auditiva pós-lingual de caráter hereditário, o padrão de herança mais frequente é o dominante (Smith e col., 2012).

As perdas auditivas podem ser classificadas de acordo com: a manifestação clínica, a lateralidade, a idade de manifestação, a gravidade, as frequências atingidas, a evolução do quadro e a origem da deficiência. Segundo a revisão de Smith e col. (2012), de acordo com a manifestação clínica, a perda auditiva pode ser dividida em sindrômica e não sindrômica. Nos casos não sindrômicos a perda auditiva aparece isolada, sem outros sinais associados à deficiência. A perda auditiva sindrômica é caracterizada pela perda auditiva associada a outros sintomas e deficiências. A perda auditiva pode ser unilateral, quando afeta somente uma das orelhas ou bilateral, quando ambas as orelhas são afetadas. Em relação à idade de manifestação, a deficiência pode ser classificada como pré-lingual, quando ela ocorre antes do indivíduo adquirir a capacidade de falar, ou pós-lingual, quando ocorre depois do individuo adquirir a fala.

De acordo com a gravidade, a perda auditiva é classificada como sendo de grau leve, quando os limiares auditivos aumentados se situam na faixa entre 21 e 40 decibéis (dB); é moderada, quando os limiares estão na faixa entre 41 e $70 \mathrm{~dB}$; é grave, quando atingem a faixa entre 71 e $90 \mathrm{~dB}$ e profunda, quando os limiares são superiores 
a 91 dB (Davis e Silverman, 1970). Para essa classificação, são calculados os valores médios dos limiares em decibéis da melhor orelha para as frequências de 500, 1000, 2000 e 4000 Hertz (Hz) (Silman e Silverman, 1991). Se a perda for em sons agudos, denomina-se, então, perda auditiva de altas frequências. Se for em sons graves, é denominada perda auditiva em baixas frequências.

De acordo com a evolução do quadro, a perda pode ser considerada progressiva ou estacionária. No caso de ela ser progressiva, ocorre evolução com a idade para deficiência mais grave. No quadro estacionário, mantém-se a gravidade por toda a vida do individuo.

Caso o distúrbio esteja localizado na orelha externa ou média, impedindo fisicamente a captação e condução da onda sonora até o ouvido interno, a deficiência é caracterizada como sendo condutiva. Já a classificação da deficiência neurossensorial é um pouco mais complexa, pois pode decorrer de defeitos na orelha interna e/ou defeitos no sistema nervoso central e periférico. Esses casos podem ser classificados em dois tipos: na perda auditiva dita sensorial, o defeito ocorre nas células ciliadas externas da cóclea; no caso da perda auditiva neural, o defeito encontra-se nas células ciliadas internas e/ou nervo auditivo. Quando o defeito ocorre no tronco encefálico ou em outras estruturas do sistema nervoso central, há autores que denominam a perda auditiva como central (Smith e col., 2012). Entre os casos de perda auditiva neurossensorial hereditária, predominam os que são decorrentes da morte das células ciliadas da cóclea, ou seja, as sensoriais. Até o presente momento, a maioria dos produtos gênicos conhecidos relacionados à perda auditiva hereditária se expressam na cóclea.

\subsection{Perda auditiva Hereditária.}

Cerca de $70 \%$ dos casos de perda auditiva hereditária são classificados como não sindrômicos (Keats e Berlin, 1999). No que se refere à perda auditiva sindrômica, as síndromes mais frequentes que apresentam a perda auditiva como um de seus principais sintomas são as: síndrome de Waardenburg (OMIM \#193500), síndrome de Treacher Collins (OMIM \#154500), síndrome de Usher (OMIM \#276900), síndrome de Pendred (OMIM \#274600), síndrome Branquio-oto-renal (OMIM \#113650) e síndrome de Alport (OMIM \#301050). 
Já se conhecem mais de 100 lócus associados à perda auditiva não sindrômica. Entretanto, se conhece um número bem menor de genes responsáveis já identificados (Van Camp e Smith, 2012). Para o mapeamento dessas regiões, foram utilizados, ao longo dos últimos anos, principalmente os estudos de ligação em grandes famílias de indivíduos afetados por perda auditiva. Recentemente, têm sido utilizadas também as técnicas de sequenciamento massivo em paralelo (de nova geração), principalmente a análise de exomas, para se encontrar o provável gene causador da doença, com ou sem mapeamento cromossômico prévio (Rehman e col., 2010; Walsh e col., 2010; Schraders e col., 2011). As perdas auditivas hereditárias podem apresentar os seguintes tipos de herança: herança autossômica dominante, herança autossômica recessiva, herança mitocondrial, herança ligada ao cromossomo $\mathrm{X}$ dominante e recessiva e herança ligada ao cromossomo Y.

DFN são as siglas utilizadas para identificar os lócus associados à perda auditiva. Essa nomenclatura vem da palavra da língua inglesa Deafness. Os lócus são numerados de acordo com a ordem em que foram mapeados. Os lócus responsáveis por conter prováveis genes causadores de perda auditiva de herança dominante recebem a terminação $\mathrm{A}$, portanto, são os chamados DFNA, seguidos do número correspondente à ordem em que foram mapeados. Os lócus da deficiência auditiva de herança autossômica recessiva recebem a terminação B. São chamados de DFNB, seguidos do número correspondente à ordem em que foram mapeados. Os lócus mapeados no cromossomo $\mathrm{X}$ são denominados DFNX (seguidos dos números correspondentes) e o único lócus mapeado no cromossomo Y é denominado DFNY1.

\subsection{Perda auditiva de herança autossômica recessiva.}

A perda auditiva de herança autossômica recessiva corresponde a cerca de $80 \%$ dos casos de perda auditiva hereditária do tipo não sindrômica (Estivill e Gasparini, 2008). Geralmente é do tipo estacionária, pré-lingual, neurossensorial, variando de grave a profunda, atingindo todas as frequências (Campbell e col., 1997; Keats e Berlin, 1999). Existem 71 lócus mapeados (DFNB) e 45 genes identificados (Tabela $1.1)$.

Dentre todos os lócus mapeados e genes identificados, o lócus DFNB1, no qual se localiza o gene da conexina 26 (GJB2), é o mais importante, uma vez que mutações 
nesse gene correspondem a mais de 50\% dos casos de perda auditiva de herança autossômica recessiva. Em 75\% dos casos de mutação no gene GJB2 está presente a mutação c.35delG (Denoyelle e col., 1997; Wilcox e col., 1999; Sundstrom e col., 1999). A frequência de heterozigotos com a mutação c.35delG na população brasileira ouvinte foi estimada em 1\% (Sartorato e col., 2000).

Existem outros lócus que também são frequentemente encontrados como mutados em muitas famílias com perda auditiva de herança autossômica recessiva e, portanto, são os lócus pesquisados com maior frequência nos estudos moleculares de perda auditiva. São eles: DFNB4 (gene SLC26A4), DFNB9 (gene OTOF), DFNB12 (gene $C D H 23$ ), DFNB7 (gene TMC1), DFNB8 (gene TMPRSS3) e DFNB3 (gene MYO15A).

O gene SLITRK6 foi relacionado a perda auditiva tanto em humanos quanto em camundongos (Mustafa e col., 2013). No entanto ainda não foi designado um DFNB para esse gene. 
Tabela 1.1: Lócus mapeados responsáveis pela perda auditiva hereditária autossômica recessiva (modificada de Van Camp e col., 2013).

\begin{tabular}{|c|c|c|c|}
\hline Lócus & $\begin{array}{c}\text { Localização } \\
\text { cromossômica }\end{array}$ & Gene & $\begin{array}{c}\text { Referências } \\
\text { Bibliográficas }\end{array}$ \\
\hline DFNB1 & $13 q 12$ & GJB2, GJB6 & Guilford e col., 1994; Kelsell e col., 1997 \\
\hline DFNB2 & $11 \mathrm{q} 13.5$ & MYOTA & Guilford e col., 1994; Liu e col., 1997; Weil e col., 1997 \\
\hline DFNB3 & $17 \mathrm{p} 11.2$ & MYO15A & Friedman e col., 1995; Wang e col., 1998 \\
\hline DFNB4 & $7 \mathrm{q} 31$ & SLC26A4 & Baldwin e col., 1995; Li e col., 1998 \\
\hline DFNB5 & $14 q 12$ & $?$ & Fukushima e col., 1995 \\
\hline DFNB6 & 3p14-p21 & TMIE & Fukushima e col., 1995; Naz e col., 2002 \\
\hline DFNB7/DFNB11 & $9 q 13-q 21$ & $T M C 1$ & Jain e col., 1995; Scott e col., 1996; Kurima e col., 2002 \\
\hline DFNB8/DFNB10 & $21 \mathrm{q} 22$ & TMPRSS3 & Veske e col., 1996; Bonné-Tamir e col., 1996; Scott e col., 2001 \\
\hline DFNB9 & 2 p22-p23 & OTOF & Chaib e col., 1996; Yasunaga e col., 1999 \\
\hline DFNB12 & $10 \mathrm{q} 21-\mathrm{q} 22$ & $\mathrm{CDH} 23$ & Chaib e col., 1996; Bork e col., 2001 \\
\hline DFNB13 & $7 q 34-36$ & $?$ & Mustapha e col., 1998 \\
\hline DFNB14 & $7 q 31$ & $?$ & Mustapha e col., 1998 \\
\hline DFNB15 & $\begin{array}{c}3 q 21-q 25 \\
19 q 13\end{array}$ & GIPC3 & Chen e col., 1997; Charizopoulou e col., 2011 \\
\hline DFNB16 & $15 q 21-q 22$ & STRC & Campbell e col., 1997; Verpy e col., 2001 \\
\hline DFNB17 & $7 q 31$ & $?$ & Greinwald e col., 1998 \\
\hline DFNB18 & $11 \mathrm{p} 14-15.1$ & USH1C & Jain e col., 1998; Ouyang e col., 2002; Ahmed e col., 2002 \\
\hline DFNB19 & $18 \mathrm{p} 11$ & $?$ & Green e col., 1998. \\
\hline DFNB20 & 11q25-qter & $?$ & Moynihan e col., 1999 \\
\hline DFNB21 & $11 \mathrm{q}$ & TECTA & Mustapha e col., 1999 \\
\hline DFNB22 & $16 \mathrm{p} 12.2$ & OTOA & Zwaenepoel e col., 2002 \\
\hline DFNB23 & 10p11.2-q21 & PCDH15 & Ahmed e col., 2003 \\
\hline DFNB24 & $11 \mathrm{q} 23$ & $R D X$ & Khan e col., 2007 \\
\hline DFNB25 & $4 \mathrm{p} 13$ & GRXCR1 & Schraders e col., 2010 \\
\hline DFNB26 & $4 q 31$ & $?$ & Riazuddin e col., 2000 \\
\hline DFNB27 & $2 q 23-q 31$ & $?$ & Pulleyn e col., 2000 \\
\hline DFNB28 & $22 q 13$ & TRIOBP & Walsh e col., 2000; Shahin e col., 2006; Riazuddin e col., 2006 \\
\hline
\end{tabular}




\begin{tabular}{|c|c|c|c|}
\hline DFNB29 & $21 \mathrm{q} 22$ & CLDN14 & Wilcox e col., 2001 \\
\hline DFNB30 & $10 \mathrm{p} 11.1$ & $M Y O 3 A$ & Walsh e col., 2002 \\
\hline DFNBA31 & $9 q 32-34$ & WHRN & Mustapha e col., 2002; Mburu e col., 2003 \\
\hline DFNB32/DFNB82 & $1 \mathrm{p} 13.3-22.1$ & GPSM2 & Masmoudi e col., 2003; Walsh e col., 2010 \\
\hline DFNB33 & $9 \mathrm{q} 34.3$ & $?$ & Medlej-Hashim e col., 2002 \\
\hline DFNB35 & $14 \mathrm{q} 24.1-24.3$ & ESRRB & Ansar e col., 2003; Collin e col., 2008 \\
\hline DFNB36 & $1 \mathrm{p} 36.3$ & $E S P N$ & Naz e col., 2004 \\
\hline DFNB37 & $6 q 13$ & MYO6 & Ahmed e col., 2003 \\
\hline DFNB38 & $6 q 26-q 27$ & $?$ & Ansar e col., 2003 \\
\hline DFNB39 & $7 \mathrm{q} 21.1$ & $H G F$ & Schultz e col., 2009 \\
\hline DFNB40 & $22 q$ & $?$ & Delmaghani e col., 2003 \\
\hline DFNB42 & $3 q 13.31-q 22.3$ & $I L D R$ & Aslam e col., 2005; Borck e col., 2011 \\
\hline DFNB44 & $7 \mathrm{p} 14.1-\mathrm{q} 11.22$ & $?$ & Ansar e col., 2004 \\
\hline DFNB45 & $1 q 43-q 44$ & $?$ & Bhatti e col., 2008 \\
\hline DFNB46 & $\begin{array}{c}\text { 18p11.32- } \\
\text { p11.31 }\end{array}$ & $?$ & Mir e col., 2005 \\
\hline DFNB47/DFNB83 & $2 \mathrm{p} 25.1-\mathrm{p} 24.3$ & $?$ & Hassan e col., 2005 \\
\hline DFNB48 & $15 q 23-25.1$ & $?$ & Ahmad e col., 2005 \\
\hline DFNB49 & $5 q 12.3-q 14.1$ & MARVELD2 & Ramzan e col., 2004; Riazuddin e col., 2006 \\
\hline DFNB51 & 11p13-p12 & $?$ & Shaikh e col., 2005 \\
\hline DFNB53 & $6 \mathrm{p} 21.3$ & COL11A2 & Chen e col., 2005 \\
\hline DFNB55 & $4 q 12-q 13.2$ & $?$ & Irshad e col., 2005 \\
\hline DFNB59 & $2 q 31.1-q 31.3$ & PJVK & Delmaghani e col., 2006 \\
\hline DFNB61 & $7 \mathrm{q} 22.1$ & $S L C 26 A 5$ & Liu e col., 2003 \\
\hline DFNB62 & 12p13.2-p11.23 & $?$ & Ali e col., 2006 \\
\hline DFNB63 & $11 \mathrm{q} 13.2-\mathrm{q} 13.4$ & LRTOMT/COMT2 & Du e col., 2008; Ahmed e col., 2008 \\
\hline DFNB65 & 20q13.2-q13.32 & $?$ & Tariq e col., 2006 \\
\hline DFNB66/DFNB67 & $6 \mathrm{p} 21.2-22.3$ & LHFPL5 & Tlili e col., 2005; Shabbir e col., 2006; Kalay e col., 2006 \\
\hline DFNB68 & $19 \mathrm{p} 13.2$ & $?$ & Santos e col., 2006 \\
\hline DFNB71 & $8 \mathrm{p} 22-21.3$ & $?$ & Chishti e col., 2009 \\
\hline
\end{tabular}

Continuação da tabela 1.1. 


\begin{tabular}{|c|c|c|c|}
\hline DFNB72 & $19 \mathrm{p} 13.3$ & GIPC3 & Ain e col., 2007; Rehman e col., 2011 \\
\hline DFNB73 & $1 \mathrm{p} 32.3$ & $B S N D$ & Riazuddin e col., 2009 \\
\hline DFNB74 & $12 q 14.2-q 15$ & $M S R B 3$ & Waryah e col., 2009; Ahmed e col., 2011 \\
\hline DFNB77 & $18 \mathrm{q} 12-\mathrm{q} 21$ & LOXHD1 & Grillet e col., 2009 \\
\hline DFNB79 & $9 \mathrm{q} 34.3$ & $T P R N$ & Rehman e col., 2010 \\
\hline DFNB81 & $19 p$ & $?$ & Rehman e col., 2011 \\
\hline DFNB84 & $12 \mathrm{q} 21.2$ & $P T P R Q, O T O G L$ & Schraders e col., 2010; Yariz e col., 2012 \\
\hline DFNB85 & $17 \mathrm{p} 12-\mathrm{q} 11.2$ & $?$ & Shahin e col., 2010 \\
\hline DFNB89 & $16 \mathrm{q} 21-\mathrm{q} 23.2$ & KARS & Santos-Cortez e col., 2013 \\
\hline DFNB91 & $6 \mathrm{p} 25$ & SERPINB6 & Sirmaci e col., 2010 \\
\hline DFNB93 & $\begin{array}{l}\text { 11q12.3- } \\
11 q 13.2\end{array}$ & $?$ & Tabatabaiefar e col., 2011 \\
\hline DFNB95 & $19 \mathrm{p} 13$ & GIPC3 & Charizopoulou e col., 2011 \\
\hline DFNB96 & 1p36.31-p36.13 & $?$ & Ansar e col., 2011 \\
\hline DFNB98 & $21 q 22,3-1$ ter & $T S P E A R$ & Delmaghani e col., 2012 \\
\hline
\end{tabular}

Continuação da tabela 1.1.

\subsection{Perdas auditivas de herança ligada ao cromossomo $X$}

Correspondem a cerca de 2 a $3 \%$ dos casos de perda auditiva hereditária (Van Camp e col., 1997). Já foram mapeados cinco lócus e identificados três genes, até o momento (Tabela 1.2).

O lócus mais frequentemente associado aos casos de perda auditiva de herança ligada ao cromossomo X é o lócus DFN3, onde se localiza o gene POU3F4. Esse gene codifica um fator de transcrição (Willens, 2000). Esse tipo de deficiência é classificada como mista, pois pode ocorrer a fixação do estribo. A maior importância da prévia identificação de mutações nesse gene é o fato de que nesses pacientes ocorre vazamento da perilinfa quando se executa a retirada do estribo (estapedectomia), um processo cirúrgico simples e muito utilizado em casos onde a deficiência é decorrente de problemas no sistema de ossículos.

Tabela 1.2: Lócus mapeados responsáveis pela perda auditiva hereditária ligada ao cromossomo X (modificada de Van Camp e col., 2012). 


\begin{tabular}{llll}
\hline Lócus & $\begin{array}{l}\text { Localização } \\
\text { Cromossômica }\end{array}$ & Gene & $\begin{array}{l}\text { Referências } \\
\text { Bibliográficas }\end{array}$ \\
\hline DFNX1 & Xq22 & PRPS1 & Tyson e col., 1996; Liu e col., 2010 \\
\hline DFNX2 & Xq21.1 & POU3F4 & Brunner e col., 1988; De Kok e col., 1995 \\
\hline DFNX3 & Xq21.2 & $?$ & Lalwani e col., 1994 \\
\hline DFNX4 & Xq22 & SMPX & del Castillo e col., 1996; Huebner e col., 2011 \\
\hline DFNX5 & Xq23-q27.3 & $?$ & Wang e col., 2006 \\
\hline
\end{tabular}

\subsection{Perda auditiva de herança ligada ao cromossomo $Y$}

Foi realizado um estudo em uma grande família de origem chinesa com perda auditiva e foi observado que a perda auditiva nessa família era transmitida somente por meio de indivíduos do sexo masculino. O estudo de mapeamento através de microssatélites não encontrou sugestão de ligação com nenhum dos 22 autossomos. Foi sugerido, por conta do mecanismo de transmissão, que o padrão de herança dessa família fosse ligado ao cromossomo Y (Wang e col., 2004), mas o gene nunca foi identificado.

\subsection{Perda auditiva de herança mitocondrial}

A perda auditiva de herança mitocondrial pode ser encontrada tanto associada a síndromes como isolada. Na maioria dos casos, a perda auditiva de herança mitocondrial ocorre como um sintoma adicional em síndromes causadas por defeitos na mitocôndria. É muito comum que uma única mutação em gene mitocondrial cause vários fenótipos distintos.

Mesmo nos casos das mutações que causam deficiência não sindrômica são ocasionalmente encontrados outros sinais associados à perda auditiva. Os principais genes e mutações relacionados à surdez mitocondrial não sindrômica estão apresentadas na tabela 1.3.

Tabela 1.3: Mutações mitocondriais responsáveis por perda auditiva de herança mitocondrial do tipo não sindrômica (modificada de Van Camp e col., 2012).

\begin{tabular}{lll}
\hline Gene & Mutação & Referência Bibliográfica \\
\hline MTRNR1 & m.1555A>G & $\begin{array}{l}\text { Prezant e col., 1993; Usami e col., 1997; } \\
\text { Estivill e col., 1998 }\end{array}$ \\
\hline MTRNR1 & m.1494C>T & Zhao e col., 2004 \\
\hline MTRNR1 & 961 (diferentes mutações) & Bacino e col., 1995; Casano e col., 1999 \\
\hline MTTS1 & m.7445A>G & Reid e col., 1994; Fischel-Ghodsian e col., \\
& & 1995; Sevior e col., 1998 \\
\hline
\end{tabular}




\begin{tabular}{lll}
\hline \multirow{2}{*}{ MTTS1 } & m.7472insC & Tiranti e col., 1995; Jaksch e col., 1998a; \\
& & Jaksch e col., 1998b; Schuelke e col.,1998; \\
& & Verhoeven e col., 1999 \\
\hline MTTS1 & m.7510T>C & Hutchin e col., 2000 \\
\hline MTTS1 & m.7511T>C & Friedman e col., 1999; Sue e col., 1999 \\
\hline
\end{tabular}

Prezant e col. (1993) identificaram uma mutação mitocondrial que causava susceptibilidade à perda auditiva após administração de antibióticos do tipo aminoglicosídeos. Essa mutação estava associada também à perda auditiva dos indivíduos da mesma família que não tinham sido expostos ao antibiótico. A mutação identificada foi a m.1555A $>\mathrm{G}$, presente no gene MTRNRl que codifica a unidade $12 \mathrm{~S}$ do ribossomo mitocondrial. As demais mutações do gene MTRNR1 também estão relacionadas a possível ototoxicidade mediante administração de aminoglicosídeos

Foi realizada uma pesquisa por Abreu-Silva e col. (2006), em amostras do nosso laboratório, que indicou que cerca de $2 \%$ dos casos de perda auditiva hereditária eram devidos a mutações mitocondriais. Essa mutação também foi encontrada em muitos países (Prezant e col., 1993; Hutchin e col., 1993; Pandya e col., 1997; Gardner e col., 1997; Fischel-Ghodsian e col., 1997; El-Schahawi e col., 1997; Casano e col., 1998; Estivill e col., 1998). Os achados desse estudo mostraram que a mutação m.1555A>G é frequente na população brasileira, indicando a sua triagem em indivíduos com perda auditiva como recomendada. Essa triagem é muito importante, pois o conhecimento prévio da presença da mutação pode evitar a administração de aminoglicosídeos, evitando ou protelando, assim, o início da perda auditiva.

Outro gene mitocondrial importante, com diferentes mutações que levam à perda auditiva não sindrômica, é o MTTS1, com quatro mutações identificadas. A mutação m.7445A $>\mathrm{G}$ do gene MTTS1 pode estar associada com queratoderma palmoplantar e a mutação 7472insC do mesmo gene está associada com disfunções neurológicas, incluindo ataxia, disartria e mioclonus (Kokotas e col., 2007).

\subsection{Genes modificadores da perda auditiva hereditária}

A perda auditiva é uma doença que apresenta grande diversidade de fenótipos entre os indivíduos, mesmo dentro de uma mesma família. Essa grande diferença de fenótipos pode ser causada por fatores ambientais ou pela interação entre produtos de diferentes genes. 
Riazuddin e col., (2000) mapearam uma forma de perda auditiva não sindrômica de herança recessiva em uma família paquistanesa com consanguinidade. $\mathrm{O}$ lócus mapeado foi o DFNB26, no qual oito indivíduos afetados dessa família apresentavam um haplótipo em homozigose. Entretanto, em sete indivíduos ouvintes, foi encontrado o mesmo haplótipo em homozigose e, por isso, foram considerados não penetrantes. Riazuddin e col., (2000) mapearam, então, um lócus dominante, chamado DFNM1, em outro cromossomo, que impedia o desenvolvimento da perda auditiva nesses sete indivíduos normais.

Bykhovskaya e col., (2000) realizaram um grande estudo com famílias espanholas e italianas que sofriam de perda auditiva de herança mitocondrial do tipo neurossensorial. Foram estudados 35 indivíduos que possuíam a mutação m.1555A>G. Os estudos de mapeamento encontraram ligação do marcador D8S277 com uma região a conter um provável gene modificador. Esse foi o primeiro lócus nuclear sugerido como modificador de uma condição de herança mitocondrial, mas o gene suposto nunca foi encontrado.

\subsection{Perda auditiva de herança autossômica dominante}

Aproximadamente 10 a $20 \%$ dos casos de perda auditiva hereditária são de herança autossômica dominante do tipo não sindrômica (Guilford e col., 1994). Já foram mapeados 55 lócus e identificados 29 genes (Tabela 1.4). As perdas auditivas com este tipo de herança são na maioria pós-linguais, progressivas e neurossensoriais (Van Laer e col., 1999).

Não existe um lócus ou gene predominante no que se refere à perda auditiva de herança autossômica dominante, como ocorre na perda auditiva de herança autossômica recessiva. Por isso, o estudo molecular e a triagem das mutações nas famílias em que ocorre esse mecanismo são muito difíceis, especialmente em famílias pequenas.

Os genes já identificados como responsáveis por perda auditiva não sindrômica autossômica dominante codificam proteínas com funções diversas relacionadas com citocinese e polimerização de actina (HDIAl), junções do tipo "fenda" (GJB2, GJB3, GJB6), canais iônicos (KCNQ4), matriz extracelular ( $C O C H$ e 
TECTA), colágenos (COL11A2), fatores de transcrição (POU4F3, EYA4 e TFCP2L3), miosinas não convencionais (MYO7A, MYH9, MYO6 e MYO1A), proteína da família das caderinas com função não conhecida (DFNA5), proteínas transmembrânicas (TMCl, WFS1) e actinas (ACTG1). Esses genes e as funções de seus produtos estão resumidos na Tabela 1.5.

\subsection{Estratégias de Mapeamento de genes de surdez}

Nos últimos tempos, a metodologia favorita empregada para mapear e identificar genes responsáveis por surdez e a com mais sucesso foi a baseada na clonagem posicional. Nessa metodologia são utilizados principalmente os estudos de ligação e os pontos de quebra de rearranjos cromossômicos para identificar a posição dos genes nos cromossomos. Na clonagem posicional clássica, um determinado gene é identificado primeiramente através da descoberta da sua localização cromossômica. A primeira vez que essa metodologia foi empregada com sucesso foi na identificação do gene responsável pela distrofia muscular de Duchenne (DMD; OMIM \#310200). 
Tabela 1.4: Lócus mapeados como responsáveis por perda auditiva hereditária não sindrômica autossômica dominante (modificado de Van Camp e Smith, 2013).

\begin{tabular}{|c|c|c|c|}
\hline Lócus & $\begin{array}{l}\text { Localização } \\
\text { Cromossômica }\end{array}$ & Gene & Referências Bibliográficas \\
\hline DFNA1 & $5 q 31$ & HDIA1 & Leon e col., 1992; Lynch e col., 1997 \\
\hline DFNA2 & $\begin{array}{l}1 \mathrm{p} 35.1 \\
1 \mathrm{p} 34\end{array}$ & $G J B 3, K C N Q 4$ & Coucke e col., 1994; Kubish e col., 1999 \\
\hline DFNA3 & $\begin{array}{l}13 q 11-q 12 \\
13 q 12\end{array}$ & GJB2, GJB6 & $\begin{array}{l}\text { Chaib e col., 1994; Denoyelle e col., 1998; } \\
\text { Grifa e col., } 1999\end{array}$ \\
\hline DFNA4 & $19 q 13$ & $\begin{array}{l}\text { MYH14, } \\
\text { CEACAM16 }\end{array}$ & $\begin{array}{l}\text { Chen e col., 1997; Donaudy e col., 2004; } \\
\text { Zheng e col., } 2011\end{array}$ \\
\hline DFNA5 & $7 \mathrm{p} 15$ & DFNA5 & Van Camp e col., 1995; Van Laer e col., 1998 \\
\hline DFNA6/DFNA14/DFNA38 & $4 \mathrm{p} 16.3$ & WFS1 & $\begin{array}{l}\text { Lesperance e col., 1995; Van Camp e col., } \\
\text { 1999; Bespalova e col., 2001; Young e col., } \\
2001\end{array}$ \\
\hline DFNA7 & $1 q 21-q 23$ & $?$ & Fagerheim e col., 1996 \\
\hline DFNA8 / DFNA12 & $1 \mathrm{q} 22-24$ & TECTA & Verhoeven e col., 1997; Verhoeven e col., 1998 \\
\hline DFNA9 & $14 q 12-q 13$ & $\mathrm{COCH}$ & Manolis e col., 1996; Robertson e col., 1998 \\
\hline DFNA10 & $6 q 22-q 23$ & EYA4 & O’Neill e col., 1996; Wayne e col., 2001 \\
\hline DFNA11 & $11 \mathrm{q} 12.3-\mathrm{q} 21$ & MYO7A & Tamagawa e col., 1996; Liu e col., 1997 \\
\hline DFNA13 & $6 \mathrm{p} 21$ & COL11A2 & Brown e col., 1997; Kunst e col., $2000^{\mathrm{a}}$ \\
\hline DFNA15 & $5 q 31$ & $\mathrm{POU} 4 \mathrm{F3}$ & Vahava e col., 1998 \\
\hline DFNA16 & $2 \mathrm{q} 24$ & $?$ & Fukushima e col., 1999 \\
\hline DFNA17 & $22 q$ & MYH9 & Lawani e col., 1999; Lawani e col., 2000 \\
\hline DFNA18 & $3 q 22$ & $?$ & Bonsch e col. 2001 \\
\hline DFNA19 & 10 (pericentr.) & $?$ & Hereditary Hearing Loss Home Page \\
\hline DFNA20/DFNA26 & $17 q 25$ & ACTG1 & $\begin{array}{l}\text { Morell e col. 2000; Kemperman e col., 2004; } \\
\text { Yang e Smith } 2000\end{array}$ \\
\hline DFNA21 & $6 \mathrm{p} 21$ & $?$ & Kunst e col., 2000b \\
\hline DFNA22 & $6 \mathrm{q} 13$ & MYO6 & Melchionda e col., 2001 \\
\hline DFNA23 & $14 \mathrm{q} 21-\mathrm{q} 22$ & $?$ & Salam e col., 2000 \\
\hline DFNA24 & $4 \mathrm{q}$ & $?$ & Hafner e col., 2000 \\
\hline DFNA25 & $12 q 21-24$ & SLC17A8 & Greene e col., 1999; Ruel e col., 2008 \\
\hline DFNA27 & $4 \mathrm{q} 12$ & $?$ & Fridell e col., 1999 \\
\hline DFNA28 & $8 \mathrm{q} 22$ & GRHL2 & Anderson e col., 1999; Peters e col., 2002 \\
\hline DFNA30 & $15 q 25-26$ & $?$ & Mangino e col., 2001 \\
\hline DFNA31 & $6 \mathrm{p} 21.3$ & $?$ & Anderson e col., 1999; Snoeckx e col., 2004 \\
\hline DFNA32 & $11 \mathrm{p} 15$ & $?$ & Li e col., 2000 \\
\hline DFNA33 & 13q34-qter & $?$ & Bonsch e col., 2009 \\
\hline DFNA36 & $9 q 13-q 21$ & $T M C 1$ & Mangino e col., 2001; kurima e col., 2002 \\
\hline DFNA39 & $4 \mathrm{q} 21.3$ & $D S P P$ & Kurima e col., 2000, Xiao e col., 2001 \\
\hline DFNA41 & 12q24-qter & $?$ & Blanton e col., 2002 \\
\hline DFNA42 & $5 q 31.1-q 32$ & $?$ & Talebizadeh e col., 2000; Xia e col., 2002 \\
\hline DFNA43 & $2 \mathrm{p} 12$ & $?$ & Xiao e col., 2001; Flex e col., 2003 \\
\hline DFNA44 & $3 q 28-29$ & CCDC50 & $\begin{array}{l}\text { Modamio-Hoybjore col., 2003; Modamio- } \\
\text { Hoybjore e col., } 2007\end{array}$ \\
\hline DFNA47 & $9 \mathrm{p} 21-22$ & $?$ & D'Adamo e col., 2003 \\
\hline
\end{tabular}




\begin{tabular}{|c|c|c|c|}
\hline DFNA48 & $12 q 13-q 14$ & MYO1A & Flex e col., 2003, Donaudy e col., 2007 \\
\hline DFNA49 & $1 \mathrm{q} 21-\mathrm{q} 23$ & $?$ & Modamio-Hoybjor e col., 2003 \\
\hline DFNA50 & $7 \mathrm{q} 32.2$ & MIRN96 & D'Adamo e col,. 2003a; Mencia e col., 2009 \\
\hline DFNA51 & $9 \mathrm{q} 21$ & $T J P 2$ & D’Adamo e col,. 2003b; Walsh e col., 2010 \\
\hline DFNA52 & $4 \mathrm{q} 28$ & $?$ & Xia e col., 2002; Moreno-Pelayo e col., 2004 \\
\hline$\overline{\text { DFNA53 }}$ & $14 q 11.2-q 12$ & $?$ & Talebizadeh e col., 2000; Yan e col., 2005 \\
\hline DFNA54 & $5 q 31$ & $?$ & $\begin{array}{l}\text { Modamio-Hoybjor e col., 2004; Gurtler e col., } \\
2004\end{array}$ \\
\hline DFNA56 & $9 \mathrm{q} 31,3-34,3$ & $T N C$ & Zhao e col., 2013 \\
\hline DFNA57 & $19 \mathrm{p} 13.2$ & $?$ & Bonsch e col., 2008 \\
\hline DFNA58 & $2 \mathrm{p} 12-\mathrm{p} 21$ & $?$ & Lezirovitz e col., 2009 \\
\hline DFNA59 & $11 \mathrm{p} 14.2-\mathrm{q} 12.3$ & $?$ & Chatterjee e col., 2009 \\
\hline DFNA60 & $2 \mathrm{q} 21.3-\mathrm{q} 24.1$ & $?$ & Liu e col., 2007 \\
\hline DFNA64 & $\begin{array}{l}12 \mathrm{q} 24.31- \\
12 \mathrm{q} 24.32\end{array}$ & $S M A C / D I A B L O$ & Cheng e col., 2011 \\
\hline
\end{tabular}

Continuação da tabela 1.4. 
Tabela 1.5: Genes identificados responsáveis por perda auditiva autossômica dominante não sindrômica, suas funções e efeitos das mutações identificadas.

\begin{tabular}{|c|c|c|c|c|c|}
\hline Lócus & Gene & Produto & Função & Consequência & Referências \\
\hline & $C R Y M$ & Crystallin, $M U$. & $\begin{array}{l}\text { Se liga ao hormônio da } \\
\text { tireoide T3 }\end{array}$ & $\begin{array}{l}\text { Disfunção auditiva através da perda } \\
\text { da capacidade de ligação com o } \\
\text { hormônio T3. }\end{array}$ & Abe e col., 2003 \\
\hline DFNA1 & DIAPHI & Diaphanous 1. & $\begin{array}{l}\text { Polimerização das fibras } \\
\text { de actina nas células } \\
\text { ciliadas da cóclea. }\end{array}$ & $\begin{array}{l}\text { Malformação do citoesqueleto de } \\
\text { actina. }\end{array}$ & Lynch e col., 1997 \\
\hline DFNA2A & $K C N Q 4$ & $\begin{array}{l}\text { Potassium channel, voltage-gated, kqt-like } \\
\text { subfamily, member } 4 .\end{array}$ & $\begin{array}{l}\text { Formação de canais de } \\
\text { potássio. }\end{array}$ & Desequilíbrio da homeostase iônica. & Kubisch e col., 1999 \\
\hline DFNA2B & GJB3 & Conexin 31. & Junções GAP & Falha na comunicação entre células. & Xia e col., 1998 \\
\hline DFNA3A & $G J B 2$ & Conexin 26. & Junções GAP & Falha na comunicação entre células. & Kelsell e col., 1997 \\
\hline DFNA3B & GJB6 & Conexin 30. & Junções GAP & Falha na comunicação entre células. & Grifa e col., 1999 \\
\hline DFNA4 & MYH14 & Myosin heavy chain 14. & $\begin{array}{l}\text { Interações com } \\
\text { citoesqueleto, regulando } \\
\text { citocinese, mobilidade e } \\
\text { polaridade celular. }\end{array}$ & Malformação dos estereocílios. & Donaudy e col., 2004 \\
\hline DFNA5 & DFNA5 & DFNA5. & $?$ & $?$ & Van Laer e col., 1998 \\
\hline $\begin{array}{l}\text { DFNA6/DFNA14/ } \\
\text { DFNA38 }\end{array}$ & WFS1 & WFS1. & $\begin{array}{l}\text { Formação de canais } \\
\text { iônicos }\end{array}$ & Desequilíbrio da homeostase iônica. & $\begin{array}{l}\text { Bespalova e col., 2001; } \\
\text { Ypoung e col., } 2001\end{array}$ \\
\hline
\end{tabular}




\begin{tabular}{|c|c|c|c|c|c|}
\hline DFNA8/DFNA12 & TECTA & Tectorin, Alpha. & $\begin{array}{l}\text { Componente da membrana } \\
\text { tectória. }\end{array}$ & $\begin{array}{l}\text { Falha da transmissão de estímulos } \\
\text { sonoros a serem convertidos em } \\
\text { sinais elétricos. }\end{array}$ & Verhoeven e col., 1998. \\
\hline DFNA9 & $\mathrm{COCH}$ & Cochlin. & $\begin{array}{l}\text { Depósito de } \\
\text { mucopolissacarídeos. }\end{array}$ & $\begin{array}{l}\text { Malformação da matriz } \\
\text { extracelular. }\end{array}$ & Robertson e col., 1998 \\
\hline DFNA10 & EYA4 & Eyes absent 4. & $\begin{array}{l}\text { Associação com proteínas } \\
\text { diversas e estimula a } \\
\text { resposta do sistema imune. }\end{array}$ & $\begin{array}{l}\text { Falha no desenvolvimento do } \\
\text { Órgão de Corti. }\end{array}$ & Wayne e col., 2001 \\
\hline DFNA11 & $M Y O 7 A$ & Myosin VIIA & Mobilidade do estereocílio. & Malformação das células ciliadas. & Liu e col., 1997 \\
\hline DFNA13 & COL11A2 & Collagen, Type XI, Alpha-2. & $\begin{array}{l}\text { Componente da membrana } \\
\text { tectória. }\end{array}$ & $\begin{array}{l}\text { Falha da transmissão de estímulos } \\
\text { sonoros a serem convertidos em } \\
\text { sinais elétricos. }\end{array}$ & McGuirt e col., 1999 \\
\hline DFNA15 & POU4F3 & $\begin{array}{l}\text { Pou domain, Class 4, Transcription Factor } \\
3 .\end{array}$ & $\begin{array}{l}\text { Interação com a proteína } \\
\text { Gfi1. }\end{array}$ & Degeneração das células ciliadas. & Vahava e col., 1998. \\
\hline DFNA17 & MYH9 & Myosin, Heavy chain 9. & Mobilidade celular. & Desorganização das redes de actina. & Lalwani e col., 2000 \\
\hline DFNA20/DFNA26 & $A C T G 1$ & Actin, Gamma-1. & $\begin{array}{l}\text { Componente do } \\
\text { citoesqueleto. }\end{array}$ & $\begin{array}{l}\text { Desorganização de várias estruturas } \\
\text { cocleares. }\end{array}$ & $\begin{array}{l}\text { Zhu e col., 2003; van } \\
\text { Wijk e col., } 2003\end{array}$ \\
\hline DFNA21 & $T J P 2$ & Tight junction protein 2. & $\begin{array}{l}\text { Organização de junções } \\
\text { intercelulares. }\end{array}$ & $\begin{array}{l}\text { Leva à morte celular programada } \\
\text { (apoptose). }\end{array}$ & Walsh e col., 2010. \\
\hline DFNA22 & MYO6 & Myosin VI & Mobilidade celular. & $\begin{array}{l}\text { Falha no transporte de substâncias } \\
\text { intra celulares para as células } \\
\text { ciliadas. }\end{array}$ & Melchionda e col., 2001 \\
\hline DFNA28 & GRHL2 & Grainyhead-like 2. & $?$ & $?$ & Peters e col., 2002 \\
\hline DFNA36 & $T M C 1$ & Transmembrane channelolike protein 1. & Proteína transmembrânica. & $\begin{array}{l}\text { Malfuncionamento das células } \\
\text { ciliadas. }\end{array}$ & Kurima e col., 2002. \\
\hline
\end{tabular}




\begin{tabular}{|c|c|c|c|c|c|}
\hline DFNA44 & $C C D C 50$ & Coiled-coil domain-containing protein 50. & $\begin{array}{l}\text { Desenvolvimento da } \\
\text { orelha interna. }\end{array}$ & Malformação da orelha interna. & $\begin{array}{l}\text { Modamio-Hoybjor e } \\
\text { col., } 2007\end{array}$ \\
\hline DFNA48 & MYOIA & Myosin IA & Mobilidade celular. & Perda da capacidade motora. & Donaudy e col., 2003 \\
\hline DFNA50 & MIRN96 & MicroRNA & $\begin{array}{l}\text { Estabiliza a tradução de } \\
\text { mRNAs. }\end{array}$ & $\begin{array}{l}\text { Altera a capacidade de manter a } \\
\text { expressão gênica das células } \\
\text { ciliadas. }\end{array}$ & Mencia e col., 2009 \\
\hline DFNA56 & $T N C$ & Tenascin $C$ & $\begin{array}{l}\text { Proteína da matriz } \\
\text { extracelular }\end{array}$ & $\begin{array}{l}\text { Altera o desenvolvimento correto } \\
\text { da cóclea. }\end{array}$ & Zhao e col., 2013 \\
\hline DFNA64 & SMAC/SIABLO & Direct IAP-binding protein with low pI. & Regulação da apoptose. & Leva à morte celular programada. & Cheng e col., 2011 \\
\hline
\end{tabular}

Continuação da tabela 1.5. 
Esse tipo de estudo necessita de famílias com muitos indivíduos afetados e fenotipicamente normais. Inicialmente o estudo da família visa identificar uma determinada região candidata a conter o gene através de estudos de segregação com marcadores moleculares do tipo microssatélites ou SNPs, para a obtenção dos haplótipos que segregam com a doença em cada membro da família estudada. Cálculos estatísticos são realizados com a finalidade de determinar se a ligação do haplótipo com o fenótipo é significativa. Nesse caso, o cálculo utilizado é o Lod Score, que é o logaritmo da probabilidade de se observar o padrão de segregação de genótipos no heredograma em variadas frequências de recombinação dividida pela probabilidade de observar a mesma segregação de genótipos se a frequência de recombinação fosse igual a 0,5 (segregação independente). Por convenção, um valor de $\operatorname{Lod}$ superior a $+3,00$ é aceito como prova de ligação estatisticamente significativa. Esse valor significa que a probabilidade do marcador genético estar ligado ao lócus do fenótipo é 1000 vezes maior do que a probabilidade de ocorrer segregação independente entre eles. Lod Scores iguais ou inferiores a $-2,00$ são considerados indicativos de exclusão de ligação.

Os estudos de ligação apresentam como desafio o fato de que os tamanhos das regiões candidatas mapeadas geralmente são grandes. Após ser definida a região candidata por mapeamento, a segunda etapa realizada é a análise e avaliação dos genes localizados na região mapeada. Atualmente, há vários navegadores genômicos que auxiliam nos estudos dos genes candidatos e de suas funções (http://www.ensembl.org/, http://genome.ucsc.edu/, http://bioviz.org/igb/, dentre outros).

Outra metodologia frequentemente utilizada para identificar genes por clonagem posicional é partir de anomalias cromossômicas. Algumas vezes, elas não somente indicam a região candidata, como podem apontar diretamente o gene responsável pelo fenótipo, caso seja possível identificar com precisão os pontos de quebra. 
Algumas alterações cromossômicas podem parecer equilibradas por técnicas cromossômicas convencionais, mas, na verdade, elas não estão equilibradas ao nível molecular. Nesses casos, a perda de bases pode não ser visualizada por estratégias de microscopia, sendo essas alterações submicroscópicas. Foi o caso do mapeamento do gene responsável pela síndrome brânquio-otorrenal (BOR; OMIM\#113650; Abdelhak e col., 1997), identificado em um paciente que apresentava uma deleção. Para identificar microdeleções e microduplicações cromossômicas as técnicas de hibridação genômica comparativa são muito úteis (Array-CGH, array-comparative genomic hybridization; Vissers e col., 2003).

\subsection{Estratégias de sequenciamento de genes.}

Desde o desenvolvimento das primeiras técnicas de sequenciamento, o aumento da capacidade e da velocidade de sequenciar genes trouxe uma enorme contribuição para a ciência da genética. Entretanto, as técnicas eram inicialmente caras e o processo para sequenciar muitos genes era demorado e laborioso (Moorthie e col., 2011), especialmente quando se utilizavam as técnicas convencionais.

Nos últimos anos, a necessidade de se utilizar técnicas de sequenciamento de genes para rotinas laboratoriais impulsionou cada vez mais o desenvolvimento de novas plataformas de sequenciamento, acompanhadas de tecnologias de apoio relacionadas à análise dos dados. Estes métodos reduziram os custos de sequenciamento do genoma humano inteiro, tornando possível o uso dessas metodologias na pesquisa e na rotina laboratorial (Moorthie e col., 2011).

Os métodos de sequenciamento de DNA foram categorizados em três gerações (Petterson e col., 2009):

A primeira geração de sequenciamento de DNA foi a padronizada por Sanger e col. (1977), predominante desde a década de 70. Tal metodologia se caracteriza pelo fato de que cada reação de sequenciamento visa um único alvo pré-definido isoladamente, o que torna a tarefa de sequenciar todo o genoma trabalhosa e cara. 
Os princípios básicos do sequenciamento do DNA se mantêm constantes desde o popular método descrito por Sanger. Desde então, algumas modificações foram feitas, como por exemplo, o uso de marcadores fluorescentes de cores diferentes para cada base, ao invés de isótopos radioativos (Smith $e$ col., 1986) e a substituição da eletroforese em gel pela eletroforese automática em capilar (Luckey e col., 1990). No entanto, apesar dessas técnicas terem representado a era de ouro do diagnóstico clínico e do sequenciamento do genoma humano, tais metodologias ainda são muito trabalhosas (Moorthie e col., 2011).

A segunda ou nova geração de sequenciamento se baseia no "sequenciamento massivo em paralelo" ou "Massive Parallel Sequencing". Ela possui uma capacidade de produzir pelo menos 100 vezes mais informação se comparada às técnicas convencionais de sequenciamento baseadas no método de Sanger nos aparelhos mais modernos (Shekhar e col., 2011). O DNA a ser sequenciado é fragmentado e inserido em uma placa de array onde cada espaço identificável contém uma sonda que se une a somente um fragmento do DNA a ser sequenciado. Dependendo da tecnologia utilizada, um único array de sequenciamento pode conter milhões ou bilhões de espaços identificáveis que amplificam e posteriormente sequenciam os fragmentos gerados, que se ligam as sondas presentes em cada espaço. São obtidas várias sequências, geralmente curtas, para cada fragmento (sequence reads). Ferramentas computacionais alinham cada sequence read com um genoma de referência, montando a sequência de DNA completa do indivíduo. Portanto, uma cobertura ampla e múltipla é necessária para se analisar completamente e com uma maior segurança a sequência completa da amostra (Moorthie e col., 2011).

Desde o surgimento das metodologias de sequenciamento "chamadas" de nova geração ou segunda geração, três métodos são os mais utilizados até os dias atuais (Moorthie e col., 2011).

Um dos métodos é chamado de terminação reversível e é empregado na plataforma Illumina (Illumina INC., San Diego, CA, USA). Outro método é o chamado de pirosequenciamento e é empregado na plataforma Roche 454 (454 
Life Sciences, Brandford, CT, USA) e o último método é chamado de sequenciamento por ligação e é empregado na plataforma ABI SOLID (Applied Biosystems, Foster City, CA, USA).

Outra geração de sequenciamento, a chamada "terceira geração" ainda está em fase de testes. Apesar de existirem algumas plataformas em uso, sua utilização ainda não é muito confiável. Essas técnicas são denominadas de "sequenciamentos novos de nova geração". Essas tecnologias se baseiam no sequenciamento em tempo real de moléculas de DNA sem a necessidade de amplicons para que ocorram (Moorthie e col., 2011). Com a manipulação de substâncias em nanoescala e o mínimo uso de compostos bioquímicos, o sequenciamento ocorre, então, a partir de uma simples molécula de DNA, sem a necessidade dessa molécula ser submetida a uma prévia amplificação via PCR (Shekhar e col., 2011).

1.11. Contribuição do sequenciamento de nova geração à identificação de genes de perda auditiva.

Doenças monogênicas e doenças genéticas multifatoriais foram, por muito tempo, estudadas por estudos de ligação e de associação, seguidas de técnicas de sequenciamento baseadas no método de Sanger para a identificação dos genes responsáveis pelos fenótipos. Mesmo com inúmeros laboratórios empenhados em identificar novos genes relacionados à perda auditiva, após vinte anos de pesquisas, menos da metade dos genes nos lócus já mapeados de surdez foram identificados.

Atualmente, as técnicas conhecidas como "sequenciamento de nova geração" tendem a substituir as técnicas de sequenciamento convencionais, devido à complexidade do sistema auditivo e da enorme heterogeneidade genética encontrada na perda auditiva. $\mathrm{O}$ sequenciamento de nova geração permite a análise de um grande número de genes candidatos de uma só vez. Além do mais, esses conjuntos de técnicas não necessitam obrigatoriamente de amostras de DNA de muitos indivíduos das grandes famílias de afetados, como é necessário nos estudos de ligação (Brownstein e col., 2012). 
Rehman e col. (2010) foram os primeiros a utilizar as técnicas de sequenciamento de nova geração para a identificação de um gene relacionado à perda auditiva em uma região previamente mapeada e refinada, por mapeamento por ligação com base em SNPs. O lócus responsável pela doença havia sido mapeado em uma região de 2,9Mb, que contém 108 genes codificadores de proteínas, na região cromossômica 9q43.3. Foi utilizado um kit de enriquecimento desenhado para sequenciar toda essa região mapeada. Oito variantes foram selecionadas para serem validadas por sequenciamento baseado no método de Sanger. Uma única variante foi confirmada, uma mutação no gene $T P R N$, que codifica a proteína taperina. A variante não foi encontrada em amostras controles adequadas. A proteína taperina possui similaridade com a proteína fostensina, que funciona como uma "capa" na extremidade terminal dos filamentos de actina do citoesqueleto. É sabido que essa proteína participa na modelagem do filamento de actina do citoesqueleto (Shearer e col., 2011).

Em um outro estudo, Brownstein e col. (2011), desenvolveram uma plataforma para sequenciamento e identificação de mutações em 246 genes conhecidos de perda auditiva em probandos com perda auditiva em famílias do Oriente Médio. Diversas mutações foram encontradas nesse estudo, revelando a enorme utilidade clínica desse tipo de análise.

Em uma escala maior, técnicas de sequenciamento de exomas (todos os exons do genoma) são consideradas extremamente promissoras. Estima-se que cerca de $60 \%$ dos genes responsáveis por doenças mendelianas possam ser identificados por meio dessas técnicas (Gilissen e col., 2012).

Em associação com as técnicas de "nova geração", as técnicas clássicas de mapeamento gênico continuam ainda a ser utilizadas para auxiliar na identificação de genes, uma vez que os estudos de ligação fornecem resultados que diminuem a região candidata a conter o gene responsável pela perda auditiva, facilitando muito a filtragem e interpretação dos resultados oriundos das análises de exomas. A combinação dessas técnicas foi utilizada para identificar o gene responsável pela perda auditiva de herança autossômica recessiva no lócus 
DFNB82. Walsh e col. (2010) utilizaram um kit de cobertura para todos os exons no probando dessa família, em cuja amostra 93\% dos genes codificadores de proteínas presentes na região mapeada foram sequenciados. Análises bioinformáticas indicaram 80 variantes em homozigose dentro do intervalo do DFNB82. Dessas variantes, sete não eram descritas, e, dessas, apenas duas alteravam a sequência dos aminoácidos. Uma das variantes foi identificada como um polimorfismo após ser encontrada em vários controles ouvintes enquanto que a outra, uma mutação no gene GPSM2, estava ausente nos controles e segregava com o fenótipo na família. O produto desse gene é expresso nas células ciliadas e de suporte da cóclea em desenvolvimento de camundongos, assim como no sáculo, utrículo e na crista da cóclea em camundongos maduros (Walsh e col., 2010).

Em um outro estudo, Zheng e col. (2011) utilizaram o sequenciamento de exoma para encontrar o gene responsável pela perda auditiva em uma família que teve a região previamente mapeada e denominada DFNA4 (Chen e col., 1995). Através de sequenciamento baseado no método de Sanger, foi identificada uma variante em potencial a explicar o quadro no gene CEACAM16 (Zheng e col., 2011). Para excluir outras possíveis variantes na região do DFNA4, foi realizado sequenciamento de nova geração, onde $98,2 \%$ de todos os exons compreendidos pela região mapeada foram sequenciados e 70,2\% dos genes codificadores de proteínas foram completamente analisados. Das variantes encontradas, muitas eram polimorfismos sem efeito, falsos positivos ou não segregavam com o fenótipo. Assim, o melhor candidato foi o gene CEACAM16. O produto desse gene é expresso na cóclea e pode estar envolvido na ligação dos estereocílios com a membrana tectória (Zheng e col., 2011).

Schraders e col. (2011) e Huebner e col. (2011), por meio de sequenciamento de exomas, encontraram uma mutação no gene $S M P X$, mapeado no lócus DFNX4, o que levou a indicação desse gene como o candidato mais provável a ser o causador da perda auditiva em uma família holandesa com perda auditiva progressiva ligada ao cromossomo $\mathrm{X}$. Foi utilizado um kit para 
sequenciamento de nova geração específico para o cromossomo X. Foram encontradas duas variantes, sendo uma delas, uma mutação sem sentido localizada no gene $S M P X$, a única a segregar com o fenótipo na família e estar ausente nos controles. Foi feita uma triagem da mutação em 26 probandos de famílias com perda auditiva ligada ao cromossomo $\mathrm{X}$ e foi encontrada essa mutação em uma segunda família, o que confirmou o papel do gene como responsável pela perda auditiva no lócus DFNX4. Porém, esse gene inicialmente não foi considerado um candidato muito forte, uma vez que sua proteína atua no músculo estriado. Após diversas análises, foi verificado que esse gene também se expressa na cóclea e seu produto tem um papel no desenvolvimento e/ou manutenção das células ciliadas (Schraders e col., 2011; Huebner e col., 2011).

Delmaghani e col., (2012) estudaram uma família iraniana, com casamentos consanguíneos, afetada por perda auditiva de herança autossômica recessiva. Nesse estudo, foi mapeado um novo lócus DFNB98 e identificado um novo gene TSPEAR. Foi utilizada previamente uma varredura genômica por SNPs para identificar a região candidata. $\mathrm{O}$ sequenciamento de todo o exoma foi realizado em três indivíduos afetados e em um indivíduo normal. Foram identificadas duas variantes (uma deleção e uma substituição de base) no gene TSPEAR. Estudos de segregação na família mostraram que essas variantes estão em homozigose nos irmãos afetados e em heterozigose nos pais, bem como ausentes em 152 amostras de controles. Foi realizado, também, o sequenciamento de todos os exons do gene TSPEAR em outras famílias iranianas afetadas por perda auditiva. No entanto, não foram identificadas outras variantes no gene que pudessem explicar os fenótipos. O produto do gene TSPEAR é expresso em diversos tecidos, incluindo a cóclea. A proteína Tspear é encontrada na superfície das células ciliadas internas e externas imaturas da cóclea (Delmaghani e col., 2012).

Zhao e col., (2013) identificaram um novo gene relacionado à perda auditiva de herança autossômica dominante em um novo lócus, nomeado DFNA56. Eles estudaram uma família chinesa composta por 70 indivíduos, dos quais 13 afetados por perda auditiva de herança autossômica dominante. Foi 
realizada uma varredura genômica com 394 microssatélites para delimitar a região candidata. Com o sequenciamento do exoma, foi identificada uma mutação missense no exon 19 do gene TNC. Os estudos da variante mostraram que ela segrega com o fenótipo e está ausente nos indivíduos normais. Para confirmar os resultados, todos os exons do gene foram sequenciados em 587 indivíduos afetados por perda auditiva sem diagnóstico genético e foi identificada uma segunda variante no mesmo exon em outra família chinesa. $\mathrm{O}$ produto do gene $T N C$ participa na formação da matriz extracelular e é extremamente conservado entre diferentes espécies, sendo expresso na membrana basilar da cóclea (Warchol e Speck, 2007).

Em vista dos resultados até agora revelados pelas técnicas de "sequenciamento de nova geração", ainda que introduzidas há pouco tempo, podemos prever uma enorme aceleração do ritmo de identificação de genes e mutações relacionados à perda auditiva, o que pode levar a uma melhora considerável do aconselhamento genético. A caracterização das proteínas codificadas por esses novos genes ou o estudo dos efeitos das novas mutações poderão trazer mais luz aos mecanismos biológicos que levam à perda auditiva. Portanto, as técnicas de "sequenciamento de nova geração" permitirão diagnósticos melhores e mais rápidos.

\section{Conclusões}

O estudo molecular das cinco famílias com surdez de herança autossômica dominante permitiu as seguintes conclusões resumidas nos parágrafos a seguir:

$\mathrm{Na}$ família 1 foi identificada uma grande duplicação não descrita no gene EYAl, associada à síndrome BOS1.

$\mathrm{Na}$ família 2, a varredura genômica com o uso de marcadores moleculares do tipo microssatélites e os resultados dos cálculos de Lod Score mapearam uma região no cromossomo 3 como a candidata a conter o gene responsável pela surdez na família. Os estudos de sequenciamento massivo em paralelo seguidos por Sanger permitiram que fosse identificada uma variante como sendo a mais provável causa da perda auditiva na família. Por se tratar de um gene nunca antes associado à perda auditiva, são necessários estudos de mais famílias e ensaios funcionais, para confirmar o papel desse gene na perda auditiva. 
Na família 3, a varredura genômica com o uso de arrays de SNP e os resultados dos cálculos de Lod Score mapearam uma região no cromossomo 20 como candidata a conter o gene responsável pela surdez na família. Os estudos de sequenciamento massivo em paralelo seguidos por sequenciamento de Sanger permitiram que fosse identificada uma variante como sendo a mais provável causa da perda auditiva na família. Por se tratar de gene nunca antes associado à perda auditiva, também são necessários estudos com outras famílias e ensaios funcionais, para confirmar o papel desse gene na perda auditiva.

$\mathrm{Na}$ família 4, a varredura genômica com o uso de arrays de SNP e os resultados dos cálculos de Lod Score mapearam duas regiões uma no cromossomo 14 e outra no cromossomo 22, como as candidatas mais prováveis a conter o gene responsável pela surdez na família. Os estudos de sequenciamento massivo em paralelo seguidos pelo sequenciamento de Sanger permitiram que fosse identificada uma variante no gene MYH9 (DFNA17) como sendo a mais provável causa da perda auditiva na família. A variante rs80338828 já foi associada à perda auditiva em dois outros estudos. Em vista desses achados, atribuímos a perda auditiva nessa família a essa variante.

Na família 5, a varredura genômica com o uso de arrays de SNP e os resultados dos cálculos de Lod Score não permitiram mapear nenhuma região candidata a conter o gene responsável pelo fenótipo devido a dificuldades computacionais. No entanto, o sequenciamento massivo em paralelo seguido do de Sanger permitiu a identificação de uma variante no gene MYO3A como sendo a mais provável candidata a explicar o fenótipo na família. O gene MYO3A corresponde ao DFNB30 e mutações nesse gene somente foram associadas à perda auditiva de herança autossômica recessiva. Apesar do padrão de herança da família por nós estudada ser o dominante, esse gene permanece como sendo o melhor candidato a explicar a perda auditiva na família por sua prévia associação com quadros de surdez. No entanto, o papel de outras variantes candidatas não pode ser completamente descartado. Estudos de segregação dessas outras 
variantes devem completar a pesquisa sobre a causa da perda auditiva nessa família.

\section{Referências Bibliográficas}

Abdelhak S, Kalatzis V, Heilig R, e col. (1997a). Clustering of mutations responsible for branchio-oto-renal (BOR) syndrome in the eyes absent homologous region (eyaHR) of EYA1. Hum. Molec. Genet. 6: 2247-2255.

Abdelhak S, Kalatzis V, Heilig R, e col (1997b). A human homologue of the Drosophila eyes absent gene underlies Branchio-Oto-Renal (BOR) syndrome and identifies a novel gene family. Nature Genet 15:157-164.

Abreu-Silva RS, Lezirovitz K, Braga MC, Spinelli M, Pirana S, Della-Rosa VA, Otto PA, Mingroni-Netto RC (2006). Prevalence of the A1555G (12S rRNA) and tRNASer (UCN) mitochondrial mutations in hearing-impaired Brazilian patients. Braz J Med Biol Res 39: 219-26.

Ahmad J, Khan SN, Khan SY e col. (2005). DFNB48, a new nonsyndromic recessive deafness locus, maps to chromosome 15q23-q25.1. Hum Genet 116: 407-12.

Ahmed ZM, Smith TN, Riazuddin S, e col. (2002). Nonsyndromic recessive deafness DFNB18 and Usher syndrome tipe IC are allelic mutations of USHIC. Hum Genet 110: 527-31.

Ahmed ZM, Morell RJ, Riazuddin S e col. (2003). Mutations of MYO6 Are Associated with Recessive Deafness, DFNB37. Am J Hum Genet 72: 131522.

Ahmed ZM, Masmoudi S, Kalay E, e col. (2008). Mutations of LRTOMT, a fusion gene with a alternative Reading frames, cause nonsyndromic deafness in humans. Nat Genet 40(11):1335-40.

Ahmed ZM, Yousaf R, Lee BC, e col. (2011). Functional null mutations of MSRB3 encoding methionine sulfoxide reductase are associated with human deafness DFNB74. Am J Hum Genet 88(1):19-29.

Ain Q, Nazli S, Riazuddin S, e col. (2007). The autosomal recessive nonsyndromic deafness locus DFNB72 is located on chromosome 19p13.3. Hum Genet 122(5):445-50.

Ali G, Santos RI, John P e col. (2006). The maping of DFNB62, a new locus for a autosomal recessive non-syndromic hearing impairment, to chromosome 12p13.2-p11.23. Clin Genet 69: 429-33.

Ansar M, Din AA, Arshad M, e col. (2003). A novel autosomal recessive nonsyndromic deafness locus (DFNB35) maps to $14 \mathrm{q} 24.1-14 \mathrm{q} 24.3$ in large consanguineous kindred from Pakistan. Eur J Hum Genet 11: 77-80.

Ansar M, Chahrour MH, Amin Ud Din M, e col. (2004). DFNB44, anovel autosomal recessive non-syndromic hearing impairment locus, maps to chromosome 7p14.1-q11.22. Hum Hered 57:195-9.

Ansar M, Lee K, Naqvi SK, e col. (2011). A new autosomal recessive nonsyndromic hearing impairment locus DFNB96 on chromosome 1p36.31-p36.13. J hum Genet 56(12):866-8. 
Anderson DW, Griffith AJ, Rudy S, San Agustin T, Friedman TB, Morell RJ (1999). A new locus for autosomal dominant hearing loss DFNA28 mapped to chomosome 8q22. 49th Annual Meeting of the American Society of Human Genetics: Program Nr: 1336 (http://www.faseb.org/genetics/ashg99/f1336.htm).

Anson BJ (1973). Embriology and anatomy of the ear. In: Paparella M, Shumrick D. Otolaryngology. Philadelphia: Saunders \& De Wesse, 1973.

Aslam M, Wajid M, Chahroud MH e col. (2005). A novel autosomal recessive nonsyndromic hearing impairment locus (DFNB42) maps to chromosome 3q13.31-q22.3. Am J Med Genet A. 133: 18-22.

Bacino C, Prezant TR, Bu X, e col. (1995). Susceptibility mutations in the mitochondrial small ribosomal RNA gene in aminoglycoside induced deafness. Pharmacogenetics 5(3):165-72.

Baldwin CT, Weiss S, Farrer RA, e col. (1995). Linkage of congenital, recessive deafness (DFNB4) to chromosome 7q31 and evidence for genetic heterogeneity in the middle eastern Druze population. Hum Mol Genet 4: 1637-1642.

Ballinger SW, Shoffner JM, Hedaya EV, e col. (1992). Maternally transmitted diabetes and deafness associated with a $10.4 \mathrm{~kb}$ mitochondrial DNA deletion. Nat Genet 1(1):11-5.

Bespalova IN, Van Camp G, Bom SJ, e col (2001). Mutations in the Wolfram syndrome 1 gene (WFS1) are a common cause of low frequency sensorineural hearing loss. Hum Mol Genet 10(22):2501-8.

Bhatti A, Lee K, McDonald ML, e col. (2008). Mapping of a new autosomal recessive non-syndromic hearing impairment locus (DFNB45) to chromosome 1q43-q44. Clin Genet 73(4):395-8.

Boie Y, Sawyer N, Slipetz DM, e col (1995). Molecular Cloning and Characterization of the Human Prostanoid DP Recepetor. The Journal of Biological Chemistry 270(32):18910-18916.

Bonapace G, Concolino D, Formicola S, Strisciuglio P (2003). A novel mutation in a patient with insulin-like growth factor 1 (IGF1) deficiency. J Med Genet 40: 913-917.

Bonne-Tamir B, DeStefano AL, Briggs CE, e col. (1996). Linkage of congenital recessive deafness (gene DFNB10) to chromosome 21q22.3. Am J Hum Genet 58: 1254-9.

Bonsch D, Scheer P, Neumann C, Lang-Roth R, Seifert E, Storch P, Weiller C, Lamprecht-Dinnesen A, Deufel T (2001). A novel locus for autosomal dominant, non-syndromic hearing impairment (DFNA18) maps to chromosome 3q22 immediately adjacent to the DM2 locus. Eur J Hum Genet 9:165-70.

Borck G, Ur Rehman A, Lee K, e col. (2011). Loss-of-function mutations of ILDR1 cause autosomal-recessive hearing impairment DFNB42. Am J Hum Genet $88(2): 127-37$. 
Bork JM, Peters LM, Razuddin S, e col. (2001). Usher syndrome 1D and nonsyndromic autosomal recessive deafness DFNB12 are caused by allelic mutations of the novel cadherin-like gene CDH23. Am J Hum Genet 68: 2637.

Braga MCC, Otto PA, Spinelli M (1999). Recurrence Risks in cases of Nonsyndromic Deafness. Braz J Dys and Speech-ear d Dis 2:33-40.

Brownstein Z, Bhonker Y e Avraham KB (2011). High-throughput sequencing to decipher the genetic heterogeneity of deafness. Genoma Beiology 13:245-54.

Brownstein Z, Bhonker Y, Avraham KB (2012). High-throughput sequencing to decipher the genetic heterogeneity of deafness. Genome Biol 13(5):245.

Bykhovskaya Y, Estivill X, Taylor K, e col. (2000). Candidate locus for a nuclear modifier gene for maternally inherited deafness. Am J Hum Genet 66(6):1905-10.

Calzolari E, Sensi A, Gualandi F (2001). Protocol for syndromal disorders associated with hearing impairment. In: Martini A, Mazzoli M, Stephens D, Read A. Definitions, Protocols and Guidelines in Genetic Hearing Impairment: 50-71.

Campbell D A, MacHale D P, Brown K A, Moynihan L M, Houseman M, Karbani G, Parry G, Janjua A H, Newton V, Al-Gazali L, Markhan A F, Lench N J, Mueller R F (1997). A new locus for non-syndromal recessive, sensorineural hearing loss (DFNB16) maps to human chromosome 15q21q22. J Med Genet 34: 1015-1017.

Carlson NR (1998). Physiology of behavior. $6^{\mathrm{a}}$ ed. Allyn and Bacon, Boston.

Casano RA, Johnson DF, Bykhovskaya Y, e col. (1999). Inherited susceptibility to aminoglycoside ototoxicity: genetic heterogeneity and clinical implications. Am J Otolaryngol 20(3):151-6.

Cediel R, Riquelme R, Contreras J, e col (2006). Sensorineural hearing loss in insulin-like growth factor I-null mice: a new model of human deafness. European Journal of Neuroscience 23:587-590.

Chaib H, Lina-Granade G, Guilford P, Plauchu H, Levilliers J, Morgon A, Petit C (1994). A gene responsible for a dominant form of neurosensory nonsyndromic deafness maps to the NSRD1 recessive deafness gene interval. Hum Mol Genet 3: 2219-22.

Chaib H, Place C, Salem N e col. (1996a). A gene responsible for a sensorineural nonsyndromic recessive deafness maps to chromosome 2q22-23. Hum Mol Genet 5: 155-8.

Chaib H, Place C, Salme N, e col. (1996b). Mapping of DFNB12, a gene for a nonsyndromal autosomal recessive deafness, to chromosome 10q21-22. Hum Mol Genet 5:1061-4.

Charizopoulou N, Lelli A, Schraders M, e col. (2011). Gipc3 mutations associated with audiogenic seizures and sensorineural hearing loss in mouse and human. Nat Commun 2:201.

Chen, A, Francis, M., Ni, L, e col (1995). Phenotypic manifestations of branchiootorenal syndrome. Am. J. Med. Genet 58: 365-370. 
Chen A, Wayne S, Bell A, e col. (1997). New gene for autosomal recessive nonsyndromic hearing loss maps to either chromosome 3q or 19p. Am J Med Genet 71: 467-71.

Chen AH, Ni L, Fukushima K, Marietta J, O'Neill M, Coucke P, Willems P, Smith RJ (1997). Linkage of a gene for dominant non-syndromic deafness to chromosome 19. Hum Mol Genet 4:1073-6.

Chen W, Kahrizi K, Meyer NC, e col. (2005). Mutation of COL11A2 causes autosomal recessive non-syndromic hearing loss at the DFNB53 locus. J Med Genet 42:e61.

Cheng J, Zhu Y, He S, Lu Y, Chen J, Han B, Petrillo M, Wrzeszczynski KO, Yang S, Dai P, Zhai S, Han D, Zhang MQ, Li W, Liu X, Li H, Chen ZY, Yuan H. (2011). Functional Mutation of SMAC/DIABLO enconding a mitochondrial proapoptotic protein, causes human progressive hearing loss DFNA64. The Am J of Human Genetics 89, 56-66.

Chishti MS, Lee K, McDonald ML, e col. (2009). Novel autosomal recessive nonsyndromic hearing impairment locus (DFNB71) maps to chromosome 8p2221.3. J Hum Genet 54(3):141-4.

ChoiBY, Park G, Gim J, e col. (2013). Diagnostic Application of Targeted Resequencing for Familial Nonsyndromic Hearing Loss. Plos One 8(8): e68692. doi: 10.1371/journal.pone.0068692.

Collin RW, Kalay E, Tariq M, e col. (2008). Mutations of ESRRB encoding estrogen-related receptor beta cause autosoma-recessive nonsyndromic hearing impairment DFNB35. Am J Hum Genet 82(1):125-38.

Cottingham RW Jr, Idury RM e Schaffer AA (1993). Faster sequential genetic linkage computations. Am J Hum Genet 53:252-63.

Coucke P, Van Camp G, Djoyodiharjo B, Smith SD, Frants RR, Padberg GW, Darby JK, Huizing EH, Cremers CW, Kimberling WJ, e col. (1994). Linkage of autosomal dominant hearing loss to the short arm of chromosome 1 in two families. $N$ Engl J Med 331: 425-31.

D'Adamo P, Donaudy F, D'Eustacchio A, Di Iorio E, Melchionda S, Gasparini P (2003a). A new locus (DFNA47) for autosomal dominant non-syndromic inherited hearing loss maps to $9 \mathrm{p} 21-22$ in a large Italian family. Eur J Hum Genet 11:121-4.

D'Adamo P, Pinna M, Capobianco S, Cesarani A, D'Eustacchio A, Fogu P, Carella M, Seri M, Gasparini P (2003b). A novel autosomal dominant non-syndromic deafness locus (DFNA48) maps to 12 q13-q14 in a large Italian family. Hum Genet 112:319-20.

Davis H e Silverman RS. Hearing and Deafness. $3^{\mathrm{a}}$ ed. New York: Holt, Rinehart e Wilson: 1970. P. 253-79.

De Kok YJ, van der Maarel SM, Bitner-Glindzicz M, e col. (1995). Association between $\mathrm{X}$-linked mixed deafness and mutations in the POU domain gene POU3F4. Science 267(5198):685-8.

Del Castillo I, Villamar M, Sarduy M, e col. (1996). A novel locus for nonsyndromic sensorineural deafness (DFN6) maps to chromosome Xp22. Hum Mol Genet 5(9):1383-7. 
Delmaghani S, Aghaie A, Compain-Nouaille S e col. (2003). DFNB40, a recessive form of sensorineural hearing loss, maps to chromosome 22q11.21-12.1. Eur J Human Genet 11: 816-8.

Delmaghani S, del Castillo FJ, Michel V, e col. (2006). Mutations in the gene encoding pejvakin, a newly identified protein of the afferent auditory pathway, cause DFNB59 auditory neuropathy. Nat Genet 38:770-8.

Delmaghani S, Aghaie A, Michalski N, e col (2012). Defect in the gene encoding the EAR/EPTP domain-containing protein TSPEAR causes DFNB98 profound deafness. Hum Mol Genet 21(17): 3835-44.

Denoyelle F, Weil D, Maw MA, Wilcox SA, Lench NJ, Allen-Powell DR, Osborn AH, Dahl HH, Middleton A, Houseman MJ, Dode C, Marlin S, BoulilaElGaied A, Grati M, Ayadi H, BenArab S, Bitoun P, Lina-Granade G, Godet J, Mustapha M, Loiselet J, El-Zir E, Aubois A, Joannard A, Petit C, e col. (1997). Prelingual Deafness: High prevalence of a 30delG mutation ion the connexin 26 gene. Hum Mol Genet 6: 217302177.

Dose AC, Burnside B (2000). Cloning and chromosomal localization of a human class III myosin. Genomics 67: 333-342.

Du X, Schwander M, Moresco EM, e col. (2008). A catechol-O-methyltransferase essential for auditory function in mice and humans. Proc Natl Acad USA 105(38):14609-14.

Durrant JD, Lovrinic JH (1995). Bases of Hearing science. 3 edição. Williams \& Wilkins. Baltimore.

Estivill X, Govea N, Barceló E, e col. (1998). Familial progressive sensorineural deafness is mainly due to the mtDNA A $1555 \mathrm{G}$ mutation and is enhanced by treatment of aminoglycosides. Am J Hum Genet 62(1):27-35.

Estivill X e Gasparini P (10/2008). The Connexin-deafness homepage. World Wide Web URL http://www.iro.es/cx26deaf.html

Fagerheim T, Nilssen O, Raeymaekers P, Brox V, Moum T, Elverland HH, Teig E, Omland HH, Fostad GK, Tranebjaerg L (1996). Identification of a new locus for autosomal dominant non-syndromic hearing impairment (DFNA7) in a large Norwegian family. Hum Mol Genet 5: 1187-91.

Fischel-Ghodsian N, Prezant TR, Fournier P, e col. (1995). Mitochondrial mutation associated with nonsyndromic deafness. Am J Otolaryngol 16(6):403-8.

Flex E, Mangino M, Mazzoli M, Martini A, Migliosi V, Colosimo A, Mingarelli R, Pizzuti A, Dallapiccola B (2003). Mapping of a new autosomal dominant non-syndromic hearing loss locus (DFNA43) to chromosome 2p12. J Med Genet 40:278-81.

Fraser FC, Sproule J R, Halal F (1980). Frequency of the branchio-oto-renal (BOR) syndrome in children with profound hearing loss. Am. J. Med. Genet 7: 341349.

Fridell RA, Boger EA, San Agustin T, Brownstein MJ, Friedman TB and Morell RJ (1999). DFNA27, a new locus for autosomal dominant hearing impairment on chromosome 4. 49th Annual Meeting of the American Society of Human $\begin{array}{llll}\text { Genetics: } & \text { Program } & \mathrm{Nr} & 1388\end{array}$ (http://www.faseb.org/genetics/ashg99/f1388.htm). 
Friedman TB, Liang Y, Weber Jl, Hinnant JT, Barber TD, e col. (1995). A gene for congenital, recessive deafness DFNB3 maps to the pericentromeric region of chromosome 17. Nat Genet 9:86-91.

Friedman RA, Bykhovskaya Y, Sue CM, e col. (1999). Maternally inherited nonsyndromic hearing loss. Am J Med Genet 84(4):369-72.

Fukuhara N, Tokiguchi S, Shirakawa K, e col. (1980). Myoclonus epilepsy associated with ragged-red fibres (mitochondrial abnormalities): disease entity or a syndrome? Light-and electron-microscopic studies of two cases and review of literature. J Neurol Sci 47(1):117-33.

Fukushima K, Ramesh A, Srisailapathy CR, e col. (1995). An autosomal recessive nonsyndromic form of sensorioneural hearing loss map to 3p-DFNB6. Genome Res 5: 305-8.

Fukushima K, Kasai N, Ueki Y, Nishizaki K, Sugata K, Hirakawa S, Masuda A, Gunduz M, Ninomiya Y, Masuda Y, Sato M, McGuirt WT, Coucke P, Van Camp G, Smith RJ (1999). A gene for fluctuating, progressive autosomal dominant nonsyndromic hearing loss, DFNA16, maps to chromosome. 2q2324.3. Am J Hum Genet 65(1):141-50.

Gasparini P, Rabionet R, Barbujani G, Melchionda S, Petersen M, Brondum-Nielsen K, Metspalu A, Oitmaa E, Pisano M, Fortina P, Zelante L, Estivill X (2000). High carrier frequency of the $35 \mathrm{delG}$ deafness mutation in European populations. Genetic Analysis Consortium of GJB2 35delG. Eur J Hum Genet 8:19-23.

Gigante M, d'Altilia M, Montemurno E, e col. (2013). Branchio-Oto-Renal Syndrome (BOR) associated with focal glomerulosclerosis in a patient with a novel EYA1 splice site mutation. Nephrology 14:60.

Gillisen C, Hoischen A, Brunner HG, e col. (2012). Disease gene identification strategies for exome sequencing. Eur J Hum Genet 20:490-497.

Gorlin RJ, Reardon W, Toriello HV (2004). Hereditary hearing loss and its syndromes. Oxford, $2^{\mathrm{a}}$ edição. 502.

Goto Y, Nonaka I, Horai S (1990). A mutatino in the tRNA(Leu)(UUR) gene associated with the MELAS subgroup of mitochondrial encephalomyopathies. Nature 348(6302):651-3.

Green e col., 1998. "The molecular Biology of Hearing and Deafness meeting Bethesda, October 8-11, 1998" (abstract 108) apud Van Camp \& Smith, 05/2003 - Hereditary Hearing Loss Home page (http://dnalabwww.uia.ac.be/dnalab/hhh/).

Greene CC, McMillan PM, Barker SE, Kurnool P, Lomax MI, Burmeister M, Lesperance MM (2001). DFNA25, a novel locus for dominant nonsyndromic hereditary hearing impairment, maps to 12q21-24. Am J Hum Genet 68:25460 .

Greinwald JH Jr, Wayne S, Chen AH, e col. (1998). Localization of a novel gene for nonsyndromic hearing loss (DFNB17) to chromosome region 7q31. Am J Med Genet 78: 107-13.

Grundfast KM, Atwood, JL, Choung D (1999). Genetics and molecular biology of deafness. Otolaryngol Clin North Am 32: 6: 1067-1088. 
Guan MX, Fischel-Ghodsian N, Attardi G. A (2000). biochemical basis for the inherited susceptibility to aminoglycoside ototoxicity. Hum Mol Genet. 9(12): 1787-93.

Guilford P, Ben Arab S, Blanchard S, Levilliers J, Weissenbach J, Belkahia A, Petit C (1994). A non-syndrome form of neurosensory, recessive deafness maps to the pericentromeric region of chromsome 13q. Hum Mol Genet 6: 24-8.

Guillausseau PJ, Massin P, Dubois_LaForque D, e col. (2001). Maternally inherited diabetes and deafness: a multicenter study. Ann Intern Med 134(9 Pt 1):721-8.

Haan EA, Hull YJ, White S, e col (1989). Tricho-rhino-phalangeal and branchio-otorenal syndrome in a family with an inherited rearrangement of chromosome 8q. Am J Med Genet 32:490-494.

Hafner FM, Salam AA, Linder TE, Balmer D, Baumer A, Schinzel AA, Spillmann T, Leal FM (2000). A novel locus (DFNA24) for prelingual nonprogressive autosomal dominant nonsyndromic hearing loss maps to 4q35-qter in a large Swiss German kindred. Am J Hum Genet 66:1437-42

Hao H, Bonilla E, Manfredi G, e col. (1995). Segregation patterns or a novel mutation in the mitochondrial tRNA glutamic acid gene associated with myopathy and diabetes mellitus. Am J Hum Genet 56(5):1017-25.

Hassan MJ, Santos RL, Rafiq MA, e col. (2005). A novel autosomal recessive nonsyndromic hearing impairment locus (DFNB47) maps to chromosome 2p25.1-p24.3. Hum genet 118:605-10.

Heimler A, Lieber E (1986). Branchio-oto-renal syndrome: reduced penetrance and variable expressivity in four generations of a large kindred. Am. J. Med. Genet 25: 15-27.

Hildebrand MS, de Silva MG, Gardner RJM, e col (2006). Cochlear implants for DFNA17 deafness. Laryngoscope 116: 2211-2215.

Hoskins BE, Cramer CH II, Silvius D, Zou D, Raymond RM Jr, Orten DJ, Kimberling WJ, Smith RJH, Weil D, Petit C, Otto EA, Xu P-X, Hildebrandt F, (2007). Transcription factor SIX5 is mutated in patients with branchio-otorenal syndrome. Am. J. Hum. Genet. 80: 800-804.

Huebner AK, Grandia M, Frommolt P, e col. (2011). Nonsense mutations in SMPX, encoding a protein responsive to physical force, result in $\mathrm{X}$-chromosomal hearing loss. Am J Hum Genet 88:621-627.

HUGO Gene Nomenclature Committee (HGNC - 08/2003), Department of Biology, University College London, Wolfson House, 4 Stephenson Way, London NW1 2HE, UK (URL: http://www.gene.ucl.ac.uk/nomenclature/).

Hutchin TP, Parker MJ, Young ID, e col. (2000). A novel mutation in the mitochondrial tRNA(Ser(UCN)) gene in a family with non-syndromic sensorineural hearing impairment. J Med Genet 37(9):692-4.

Irshad S, Santos RL, Muhammad D, e col. (2005). Localization of a novel autosomal recessive non-syndromic hearin impairment locus DFNB55 to chromosome 4q12-q13.2. Clin Genet 68:262-7.

Jain PK, Fukushima K, Deshamukh D, e col. (1995). A human recessive neurosensory nonsyndromic hearing impairment locus is potential homology of murine deafness (dn locus). Hum Mol Genet 4: 2391-4. 
Jain PK, Lalwani AK, Li XC e col. (1998). A gene for recessive nonsyndromic sensorineural deafness (DFNB18) maps to the chromosomal region 11p14p15.1 containing the Usher syndrome type 1C gene. Genomics 50:290-2.

Jaksch M, Klopstock T, Kurlemann G, e col. (1998a). Progressive myoclonus epilepsy and mitochondrial myopathy associated with mutations in the tRNA(Ser(UCN)) gene. Ann Neurol 44(4):635-40.

Jaksch M, Hofmann S, Kleinle S, e col. (1998b). A systematic mutation screen of 10 nuclear and 25 mitochondrial candidate genes in 21 patients with cytochrome c oxidase $(\mathrm{COX})$ deficiency shows tRNA(Ser)(UCN) mutations in a subgroup with syndromal encephalopathy. J Med Genet 35(11):895-900.

Jones KL e Smith (2007). Padrões reconhecíveis de malformações congênitas. Tradução Carlos André Oighesntein e col. Editora Elsevier, Rio de Janeiro, pág. 267.

Junqueira LC e Carneiro J (1999). Histologia Básica. 9a ed. Editora Guanabara Koogan S.A., Rio de Janeiro.

Kalay E, Li Y, Uzumcu A, e col. (2006). Mutations in the lipoma HMGIC fusion partner-like 5 (LHFPL5) gene cause autosomal recessive nonsyndromic hearing loss. Hum Mutat 27: 633-9.

Kameoka K, Isotani H, Tanaka K, e col. (1998). Novel mitochondrial DNA mutation in tRNA(lys) $(8296 \mathrm{~A}>\mathrm{G})$ associated with diabetes. Biochem Biophys Res Commun 245(2):523-7.

Keats BJB e Berlin CI (1999).Genomes and Hearing Impairment.Genome Res 9: 716.

Kelsell DP, Dunlop J, Stevens HP, Lench NJ, Liang JN, Parry G, Mueller RF, Leigh IM (1997). Connexin 26 mutations in hereditary non-syndromic sensorioneural deafness. Nature 387(6628):80-3.

Khan SY, Riazuddin S, Tariq M, e col. (2007). Autosomal recessive nonsyndromic deafness locus DFNB 63 at chromosome 11q13.2-q13.3. Hum Genet 120: 789-93.

Kokotas H, Petersen MB, Willens PJ. (2007). Mitochondrial Deafness. Clin Genet 71(5):379-91.

Konig R, Fuchs S, Dukiet C (1994). Branchio-oto-renal (BOR) syndrome: Variable expressivity in a five-generation pedigree. Eur J Pediatr 153:446-450.

Kumar S,Kimberling WJ, Kenyon JB, Smith RJH, Marres EHMA, Cremers CWRJ (1992). Autosomal dominant branchio-oto-renal syndrome--localization of a disease gene to chromosome $8 \mathrm{q}$ by linkage in a Dutch family. Hum. Molec. Genet. 1: 491-495.

Kunst H, Huybrechts C, Marres H, Huygen P, Van Camp G, Cremers C (2000a). The phenotype of DFNA13/COL11A2: nonsyndromic autosomal dominant mid-frequency and high-frequency sensorineural hearing impairment. Am J Otol 21:181-7.

Kunst H, Marres H, Huygen P, Van Duijnhoven G, Krebsova A, Van Der Velde S, Reis A, Cremers F, Cremers C (2000b). Non-syndromic autosomal dominant progressive non-specific mid-frequency sensorineural hearing impairment 
with childhood to late adolescence onset (DFNA21). Clin Otolaryngol. 25: 45-54.

Kurima K, Szymko Y, Rudy S, Morell RJ, Friedman TB, Griffith AJ (2000). Genetic map localization of DFNA34 and DFNA36, two autosomal dominant nonsyndromic deafness loci. 50th Annual Meeting of The American Society of Human Genetics: Program 1654 (http://www.faseb.org/genetics/ashg00/f1654.htm).

Kurima K, Peters LM, Yang Y, Riazuddin S, Ahmed ZM, Naz S, Arnaud D, Drury S, Mo J Makishima T, Ghosh M, Menon PS, Deshmukh D, Oddoux C, Ostrer H, Khan S, Riazuddin S, Deininger PL, Hampton LL, Sullivan SL, Battey JF Jr, Keats BJ, Wilcox ER, Friedman TB, Griffith AJ (2002). Dominant and recessive deafness caused by mutations of a novel gene, TMC1, required for cochlear hair-cell function. Nat Genet 30: 277-84.

Lalwani AK, Brister JR, Fex J, e col. (1994). A new nonsyndromic X-linked sensorineural hearing impairment linked to Xp21.2. Am J Hum Genet 55(4):685-94.

Lalwani AK, Luxford WM, Mhatre AN, Attaie A, Wilcox ER, Castelein CM (1999). A new locus for nonsyndromic hereditary hearing impairment, DFNA17, maps to chromosome 22 and represents a gene for cochleosaccular degeneration. Am J Hum Genet 64:318-23.

Lalwani AK, Goldstein JA, Kelley MJ, e col (2000). Human nonsyndromic hereditary deafness DFNA17 is due to a mutation in nonmuscle myosin MYH9. Am J Hum Genet 67(5):1121-8.

Lathrop GM, Lalouel JM, Julier C, e col. (1985). Multilocus linkage analysis in humans. Detection of linkage and estimation of recombination. AM J Hum Genet 37:482-498.

Lelli A, Asai Y, Forge A, e col (2009). Tonotopic gradient in the developmental acquisition of sensory transduction in outer hair cells of the mouse cochlea. $J$ Neurophysiol 101(6):2961-73.

Leon PE, Raventos H, Lynch E, Morrow J, King MC (1992). The gene for an inherited form of deafness maps to chromosome 5q31. PNSA 89:5181-5184.

Lesperance MM, Hall JW 3rd, Bess FH, Fukushima K, Jain PK, Ploplis B, San Agustin TB, Skarka H, Smith RJ, Wills M, e col (1995). A gene for autosomal dominant nonsyndromic hereditary hearing impairment maps to 4p16.3. Hum Mol Genet 4:1967-72.

Lezirovitz K, Nicastro FS, Pardono E, Abreu-Silva R S, Batissoco AC, Neustein I, Spinelli M, Mingroni-Netto RC (2006). Is autosomal recessive deafness associated with oculocutaneous albinism a coincidence syndrome? Journal of Human Genetics, v.51, p.716 - 720.

Lezirovitz K, Pardono E, Auricchio MTBM, Silva FLCE, Lopes JJ, Abreu-Silva RS, Romanos J, Batissoco AC, Mingroni-Netto RC (2008a). Unexpected genetic heterogeneity in a large consanguineous Brazilian pedigree presenting deafness. European Journal of Human Genetics, v.16, p.89 - 96.

Lezirovitz K, Maestrelli S, Cotrim NH, Otto PA, Pearson PL, Mingroni-Netto RC (2008b). A novel locus for split-hand/foot malformation associated with tibial 
hemimelia (SHFLD syndrome) maps to chromosome region 17p13.1-17p13.3. Hum Genet v. 123: 625-631.

Lezirovitz K, Braga MC, Thiele-Aguiar RS, Auricchio MT, Pearson PL, Otto PA, Mingroni-Netto RC (2009). A novel autosomal dominant deafness locus (DFNA58) maps to 2p12-p21. Clin Genet. Jan 20. [Epub ahead of print]

Li XC, Everett LA, Lawani AK, e col. (1998). A mutation in PDS causes nonsyndromic recessive deafness. Nat Genet 18(3): 251-7.

Li XC,Saal HM, Friedman TB, Friedman R A (2000). A New Gene For Autosomal Dominant Nonsyndromic Sensorineural Hearing Loss (DFNA32) Maps to 11p15. 50th Annual Meeting of The American Society of Human Genetics: Program Nr: 1727 (http://www.faseb.org/genetics/ashg00/f1727.htm).

Lin CS, Shen W, Cehn ZP, e col (1994). Identification of I-Plastin, a Human Fimbrin Isoform Expressed in Intestine and Kidney. Molecular and cellular biology Apr. 2457-2467.

Liu X, Han D, Li J, e col. (2010). Loss-of-function mutations in the PRPS1 gene cause a type of nonsyndromic X-linked sensorineural deafness, DFN2. Am J Hum Genet 86(1):65-71.

Liu XZ, Walsh J, Mburu P, e col. (1997). Mutations in the myosin VIIA gene cause non-syndromic recessive deafness. Nat Genet 16:188-90.

Liu XZ, Ouyang XM, Xia XJ, e col. (2003). Prestin. A cochlear motor protein, is defective in non-syndromic hearing loss. Hum Mol Genet 12(10):1155-62.

Liu Z, Liao L, Zhou S, Xu J (2008). Generation and Validation of a Mouse Line with a Floxed SRC-3/AIBI Allele for Conditional Knockout. Int J Biol Sci 4(4):202-207.

Luckey JA, Drossman H, Kostichka AJ (1990). High speed DNA sequencing by capillary electrophoresis. Nucleic Acids Res 11;18(15):4417-21.

Louet JF, Coste A, Amazit L, e col (2006). Oncogenic steroid receptor coactivator-3 is a key regulator of the white adipogenic program. Pro Nat Acad Sci 103: 17868-17873.

Mangino M, Flex E, Capon F, Sangiuolo F, Carraro E, Gualandi F, Mazzoli M, Martini A, Novelli G, Dallapiccola B (2001). Mapping of a new autosomal dominant nonsyndromic hearing loss locus (DFNA30) to chromosome 15q25-26. Eur J Hum Genet 9:667-71.

Manolis EN, Yandavi N, Nadol JB Jr, Eavey RD, McKenna M, Rosenbaum S, Khetarpal U, Halpin C, Merchant SN, Duyk GM, MacRae C, Seidman CE, Seidman JG (1996). A gene for non-syndromic autosomal dominant progressive postlingual sensorineural hearing loss maps to chromosome 14q12-13. Hum Mol Genet 5:1047-50.

Marres HAM, Cremers CWRJ (1991). Congenital conductive or mixed deafness, preauricular sinus, external ear anomaly, and commissural lips pits: an autosomal dominant inherited syndrome. Ann. Otol. Rhinol. Laryng: 100: 928-932.

Mausmoudi S, Tlili A, Majava M, e col. (2003). Mapping of a new autosomal recessive nonsyndromic hearing loss locus (DFNB32) to chromosome 1p13.3-22.1 Eur J Hum Genet 11: 185-8. 
Mburu P, Mustapha M, Varela A, e col. (2003). Defects in whirlin, a PDZ domain molecule involved in stereocilia elongation, cause deafness in the whirler mouse and families with DFNB31. Nat Genet 34:421-428.

Medlej-Hashinm M, Mustapha M, Chouery E, e col. (2002). Non-syndromic recessive deafness in Jordan: mapping of a new locus to chromosome 9q34.3 and prevalence of DFNB1 mutations. Eur J Hum genet 10: 391-4.

Melchionda S, Ahituv N, Bisceglia L, Sobe T, Glaser F, Rabionet R, Arbones ML, Notarangelo A, Di Iorio E, Carella M, Zelante L, Estivill X, Avraham KB, Gasparini P (2001). MYO6, the human homologue of the gene responsible for deafness in Snell's waltzer mice, is mutated in autosomal dominant nonsyndromic hearing loss. Am J Hum Genet 69(3):635-40.

MGI, Mouse Genomic Informatics. (http://www.informatics.jax.org/)

Mir A, Ansar M, Chahour MH e col. (2005). Mapping of a novel autosomal recessive nonsyndromic deafness locus (DFNB46) to chromosome 18p11.32p11.31. Am J Med Genet 133: 23-6.

Modamio-Hoybjor S, Moreno-Pelayo MA, Mencia A, del Castillo I, Chardenoux S, Armenta D, Lathrop M, Petit C, Moreno F (2003). A novel locus for autosomal dominant nonsyndromic hearing loss (DFNA44) maps to chromosome 3q28-29. Hum Genet.112:24-8.

Modamio-Hoybjor S, Moreno-Pelayo MA, Mencia A, del Castillo I, Chardenoux S, Morais D, Lathrop M, Petit C, Moreno F (2004). A novel locus for autosomal dominant nonsyndromic hearing loss, DFNA50, maps to chromosome 7q32 between the DFNB17 and DFNB13 deafness loci. J Med Genet 41:e14.

Montagna P, Gallassi R, Medori R, e col. (1988). MELAS syndrome: characteristic migrainous and epiletic features and maternal transmission. Neurology 38(5):751-4.

Moorthie S, Mattocks CJ, Wright CF (2011). Review of massively parallel DNA sequencing technologies. Huqo 5(1-4): 1-12.

Moraes CT, DiMauro S, Zeviani M, e col. (1989). Mitochondrial DNA deletions in progressive external ophthalmoplegia and Kearns-Sayre syndrome. $N$ Engl J Med 320(20):1293-9.

Morell RJ, Friderici KH, Wei S, Elfenbein JL, Friedman TB, Fisher RA (2000). A new locus for late-onset, progressive, hereditary hearing loss DFNA20 maps to 17q25. Genomics 63:1-6.

Moreno-Pelayo MA, Modamio-Høybjør S, Mencía A, del Castillo I, Chardenoux S, Fernández-Burriel M, Lathrop M, Petit C, Moreno F (2004). DFNA49, a novel locus for autosomal dominant non-syndromic hearing loss, maps proximal to DFNA7/DFNM1 region on chromosome 1q21-q23. J Med Genet 40:832-6.

Moynihan L, Houseman M, Newton V, e col. (1999). DFNB20: a novel locus for autosomal recessive, non-syndromic sensorineural hearing loss maps to chromosome 11q25-qter. Eur J Hum 7:243-6.

Mustapha M, Chardenoux S, Neider A e col. (1998a). A sensorineural progressive autosomal recessive form of isolated deafness, DFNB13, maps to chromosome 7q34-q36. Eur J Hum Genet 6: 245-50. 
Mustapha M, Salem N, Weil D, e col. (1998b). Identification of a locus on chromosome 7q31, DFNB14, responsible for prelingual sensorineural nonsyndromic deafness. Eur J Hum Genet 6:548-51.

Mustapha M, Weil D, Chadenoux S e col. (1999). An alpha-tectorin gene defect causes a newly identified autosomal recessive form of sensorineural hearing loss, maps to chromosome 9q32-43. Eur J Hum Genet 10:210-2.

Mustapha M, Chouery E, Chardenoux S, e col. (2002). DFNB31, a recessive form of sensorineural hearing loss, maps to chromosome 9q32-34. Eur J Hum genet 10:210-2.

Naz S, Giguere CM, Kohrman DC, e col. (2002). Mutations in a novel gene, TMIE, are associated with hearing loss linkage to DFNB6 locus. Am J Hum Genet 71: 632-6.

Naz S, Griffith Aj, Riazuddin S e col. (2004). Mutations of ESPN cause autosomal recessive deafness and vestibular dysfunction. J Med Genet 41: 591-5.

Ni L, Wagner MJ, Kimberling WJ, e col (1994). Refined localization of the branchiootorenal syndrome gene by linkage and haplotype analysis. Am J Med Genet 51: 176-184.

O'Neill ME, Marietta J, Nishimura D, Wayne S, Van Camp G, Van Laer L, Negrini C, Wilcox ER, Chen A, Fukushima K, Ni L, Sheffield VC, Smith RJ (1996). A gene for autosomal dominant late-onset progressive non-syndromic hearing loss, DFNA10, maps to chromosome 6. Hum Mol Genet 5:853-6.

Ouyang XM, Xia XJ, Verpy E, e col. (2002). Mutations in the alternatively spliced exons of USH1C cause non-syndromic recessive deafness. Hum Genet 111: 26-30.

Parving (1996) A. Epidemiology of genetic hearing impairment. In: Martini A, Read A, Stephens D. Genetics and Hearing Impairment: 73-81.

Pavlakis SG, Phillips PC, DiMauro S, e col. (1984). Mitochondrial myopathy, encephalopathy, lactic acidosis, and strokelike episodes: a distinctive clinical syndrome. Ann Neurol 16(4):481-8.

Peters LM, Anderson DW, Griffith AJ, Grundfast KM, San Agustin TB, Madeo AC, F4iedman TB, Morell RJ (2002). Mutation of a transcription factor, TFCP2L3, causes progressive autosomal dominant hearing loss, DFNA28. Hum Mol Genet 11:2877-2885.

Pettersson E, Lundeberg J, Ahmadian A (2009). Generations of sequencing technologies. Genomics 93:105-111.

Piatto VB e Maniglia JV (2001). Importância do gene Conexina 26 na etiologia da deficiência sensorioneural não-sindrômica. Acta Awho 20: 106-112.

PosMed, Positional Medline. (http://biolod.org/PosMed/)

Prezant TR, Agapian JV, Bohlman MC, e col. (1993). Mitochondrial ribosomal RNA mutation associated with both antibiotic-induced and non-syndromic deafness. Nat genet 4:289-294.

Pujol R, Réclar-Enjalbert V e Pujol T (2002). Promenade round the cochlea. (http://www.iurc.montp.inserm.fr/cric/audition/english/index.htm). 
Pulleyn LJ, Jackson AP, Roberts E e col. (2000). A new locus for autosomal recessive non-syndromal sensorineural hearing impairment (DFNB27) on chromosome 2q23-q31. Eur J Hum Genet 8: 991-3.

Ramzan K, Shaikh RS, Ahmad J, e col. (2004). A new locus for nonsyndromic deafness DFNB49 maps to chromosome 5q12.3-14.1. Hum Genet 116(12):17-22.

Reardon W, Ross RJ, Sweeney MG, e col. (1992). Diabetes mellitus associated with a pathogenic point mutation in mitochondrial DNA. Lancet 340(8832)1376-9.

Rehman AU, Morell RJ, Belyantseva IA, e col. (2010). Targeted capture and nextgeneration sequencing identifies C9orf75, encoding taperin, as the mutated gene in nonsyndromic deafness DFNB79. Am J Hum Genet 86(3):378-88.

Rehman AU, Gui K, Morell RJ, e col. (2011). Mutations of GIPC3 cause nonsyndromic hearing loss DFNB72 but not DFNB81 that also maps to chromosome 19p. Hum Genet 130(6):759-65.

Reid FM, Vernham GA, Jacobs HT (1994). A novel mitochondrial point mutation in a maternal pedigree with sensorineural deafness. Hum Mutat 3(3):243-7.

Riazuddin A, Castelein CM, Ahmed ZM e col. (2000). Dominant modifier DFNM1 suppresses recessive deafness DFNB26. Nat Genet 26: 431-4.

Riazuddin S, Khan SN, Ahmed ZM, e col. (2006a). Mutations in TRIOBP, xich encodes a putative cytoskeletal-organizing protein, are associated with nonsyndromic recessive deafness. Am J Hum Genet 78(1):137-43.

Riazuddin S, Ahmed ZM, Fanning AS, e col. (2006b). Tricellulin is a tight-junction protein necessary for hearing. Am J Hum Genet 79:1040-51.

Riazuddin S, Anwar S, Fischer M, e col. (2009). Molecular basis of DFNB73: mutations of BSND can cause nonsyndromic deafness os Bartter syndrome. Am J Hum Genet 85(2):273-80.

Robertson NG, Lu L, Heller S, e col (1998). Mutations in a novel cochlear gene cause DFNA9, a human nonsyndromic deafness with vestibular dysfunction. Nature Genet 20:299-303.

Rogatko A, Pereira CAB e Frota-Pessoa O (1986). A Baesyan Method for Estimation of Penetrance: Aplication to Mandibulofacial and Frontonasal Dyostoses. Am. J. Hum. Genet. 24: 231-246.

Ruf RG, Berkman J, Wolf MTF, Nurnberg P, Gattas M, Ruf E-M, Hyland V, Kromberg J, Glass I, Macmillan J, Otto E, Nurnberg G, Lucke B, Hennies HC, Hildebrandt F (2003). A gene locus for branchio-otic syndrome maps to chromosome 14q21.3-q24.3. J. Med. Genet. 40: 515-519.

Salam AA, Hafner FM, Linder TE, Spillmann T, Schinzel AA, Leal SM (2000). A novel locus (DFNA23) for prelingual autosomal dominant nonsyndromic hearing loss maps to 14q21-q22 in a Swiss German kindred. Am J Hum Genet 66:1984-8.

Sanger F, Nicklen S, Coulson AR (1977). DNA sequencing with chain-terminating inhibitors. Proc. Nati. Acad. Sci. USA 74(12):5463-67.

Santos RL, Hassan MJ, Sikandar S, e col. (2006). DFNB68, a novel autosomal recessive non-syndromic hearing impairment locusat chromosomal region 19p13.2. Hum Genet 120(1):85-92. 
Santos-Cortez RLP, Lee K, Azeem Z, e col (2013). Mutations in KARS, Encoding Lysyl-tRNA Synthetase, Cause Autosomal-Recessive Nonsyndromic Hearing Impairment DFNB89. Am J Hum Genet 1:132-140.

Sartorato EL, Gottardi E, de Oliveira CA, Magna LA, Annichino-Bizzacchi JM, Seixas CA, Maciel-Guerra AT (2000). Determination of the frequency of the 35delG allele in Brazilian neonates. Clin Genet 58: 339-40.

Schraders M, Lee K, Oostrik J, e col. (2010b). Homozygosity mapping reveals mutations of GRXCR1 as a cause of autosomal-recessive nonsyndromic hearing impairment. Am J Hum Genet 86(2):138-47.

Schraders M, Oostrik, Huygen PL, e col. (2010c). Mutations in PTPRQ are cause of autosomal-recessive nonsyndromic hearing impairment DFNB84 and associated with vestibular dysfunction. Am J Hum Genet 86(4):604-10.

Schraders M, Haas SA, Weegerink NJ, e col. (2011). Next-generation sequencing identifies mutations of $S M P X$, wich encodes the small muscle protein. Xlinked, as a cause of progressive hearing impairment. Am J Hum Genet 88:628-634.

Schuelke M, Bakker M, Stoltenburg G, e col (1998). Epilepsia partialis continua associated with a homoplasmic mitochondrial tRNA(Ser(UCN)) mutation. Ann Neurol 44(4):700-4.

Schultz JM, Khan SN, Ahmed ZM, e col. (2009). Noncoding mutations of HGF are associated with nonsyndromic hearing loss, DFNB39. Am J Hum Genet 85(1):25-39.

Scott DA, Carmi R, Elbedour K, e col. (1996). Na autosomal recessive nonsyndromic-hearing-loss locus identified by dna pooling using two inbreed Bdouin Kindreds. Am J Hum Genet 59: 385-91.

Scott RN, Kudoh J, Watternhofer M e col. (2001). Insertion of beta-satellite repeats identifies a transmembrane protease causing both congenital and childhood onset autosomal recessive deafness. Nat Genet 27: 59-63.

Sevior KB, Hatamochi A, Stewart IA, e col. (1998). Mitochondrial A7445G mutation in two pedigrees with palmoplantar keratoderma and deafness. Am J Med Genet 75(2):179-85.

Shabbir MI, Ahmed ZM, Khan SY, e col. (2006). Mutations of human TMHS cause recessively inherited non-syndromic hearing loss. J Med Genet 43:634-40.

Shahin H, Walsh T, Sobe T, e col. (2006). Mutations in a novel isoform of TRIOBP that encodes a filamentous-actin binding protein are responsible for DFNB28 recessive nonsyndromic hearing loss. Am J Hum Genet 78(1):144-52.

Shahin MI, Walsh T, Rayyan AA, e col. (2010). Five novel loci for inherited hearing loss mapped by SNP-based homozygosity profiles in Palestinian families. Eur J Hum Genet 18(4):407-13.

Shaikh RS, Ramzan K, Nazli S e col. (2005). A new locus for nonsyndromic deafness DFNB51 maps to chromosome 11p13-p12. Am J Med Genet A 138: 392-5.

Shearer AE, Hildebrand MS, Sloan CM, e col (2011). Deafness in the genomics era. Hear Res 282(1-2):1-9. 
Shekhar CP, Smoczynski R, tretyn A (2011). Sequencing technologies and genome sequencing. J Appl Genet 52(4): 413-435.

Shimasaki N, Watanabe K, Hara M, e col (2004). EYA1 Mutation in a Newborn Female Presenting with Cardiofacial Syndrome. Pediatr Cardiol 25:411-413.

Shoffner JM, Lott MT, Lezza AM, e col. (1990). Myoclonic epilepsy and ragged-red fiber disease (MERRF) is associated with a mitochondrial DNA tRNA(Lys) mutation. Cell 61(6):931-7.

Silman S, Silverman CA. Auditory diagnosis, principles and applications. London: Singular Publishing Group: 1991. P.215-32.

Smith LM, Sanders JZ, Kaise RJ (1986). Fluorescence detection in automated DNA sequence analysis. Nature 321(6071):674-9.

Smith RJH, Coppage KB, Ankerstjerne JKB, e col (1992). Localization of the gene for branchiootorenal syndrome to chromosome 8q. Genomics 14: 841-844.

Smith RJH, Shearer AE, Hildebrand MS e Van Camp G (2012). Deafness and Hereditary Hearing Loss Overview. Bookshelf ID: NBK1434 PMID: 20301607.

Son EJ, Wu L, Yoon H, e col. (2012). Developmental Gene Expression Profiling along the Tonotopic Axis of the Mouse Cochlea. PLoS ONE 7(7): e40735. doi:10.1371/journal.pone.0040735.

Spruijt L, Hoefsloot LH, van Schaijk GHWH, e col (2006). Identification of a Novel EYA1 Mutation Presenting in a Newborn With Laryngomalacia, Glossoptosis, Retrognathia, and Pectus Excavatum. Am J Med Genet 140A:1343-1345.

Stockley TL, Mendonza-Londono R, Porpst EJ, e col. (2009). A Recurrent E YA1 Mutation Causing Alternative RNA Splicing in Branchio-Oto-Renal Syndrome: Implications for Molecular Diagnostics and Disease Mechanism. Am J Med Genet 149A:322-327.

Stratakis CA, Lin J-P, Rennert OM (1998). Description of a large kindred with autosomal dominant inheritance of branchial arch anomalies, hearing loss and ear pits, and exclusion of the branchio-oto-renal (BOR) syndrome gene locus (chromosome 8q13.3). Am J Med Genet 79:209-214.

Sue CM, Tanji K, Hadjigeorgiou G, e col. (1999). Maternally inherited hearing loss in a large kindred with a novel T7511C mutation in the mitochondrial DNA tRNA(Ser(UCN)) gene. Neurology 52(9):1905-8.

Sugimoto Y, Narumiya S (2007). Prostaglandin E Receptors. The Journal of Biological Chemistry 282(16):11613-11617.

Sundstrom RA, Van Laer L, Van Camp G, Smith RJH (1999). Autossomal Recessive Nonsyndromic Hearing Loss. Am J Med Genet (Semin. Med. Genet.) 89: 123-129.

Tabatabaiefar MA, Alasti F, Shariatu L, e col. (2011). DFNB93, a novel locus for autosomal recessive moderate-to-severe hearind impairment. Cin Genet 79(6): 594-8.

Talebizadeh Z, Kenyon JB, Askew JW, Smith SD (2000). A new locus for dominant progressive hearing loss DFNA37 mapped to chromosome 1p21. 50th Annual Meeting of The American Society of Human Genetics: Program Nr: 1740 (http://www.faseb.org/genetics/ashg00/f1740.htm). 
Tamagawa Y, Kitamura K, Ishida T, Ishikawa K, Tanaka H, Tsuji S, Nishizawa M (1996). A gene for a dominant form of non-syndromic sensorineural deafness (DFNA11) maps within the region containing the DFNB2 recessive deafness gene. Hum Mol Genet 5:849-52.

Tariq A, Santos RI, Khan MN e col. (2006). Localization of a novel autosomal recessive nonsyndromic hearing impairment locus DFNB65 to chromosome 20q13.2-13.32. J Mol Med 84: 484-90.

Tiranti V, Chariot P, Carella F, e col (1995). Maternally inherited hearing loss, ataxia and myoclonus associated with a novel point mutation in mitochondrial tRNASer(UCN) gene. Hum Mol Genet 4(8):1421-7.

Tlili A, Mannikko M, Charfedine I e col. (2005). A novel autosomal recessive nonsyndromic deafness locus, DFNB66, maps to chromosome 6p21.2-22.3 in a large Tunisian consaguineous family. Hum Hered 60: 123-8.

Tomek MS, Brown MR, Mani SR, Ramesh A, Srisailapathy CRS, Coucke P, Zbar RIS, Bell AM, McGuirt WT, Fukushima, Willems PJ, Van Camp, Smith RJH (1998). Localization of a gene for otosclerosis to chromosome 15q25q26. Hum Mol Genet 7: 285-90.

Usami S, Abe S, Kasai M, e col. (1997). Genetic and clinical features of sensorineural hearing loss associated with the 1555 mitochondrial mutation. Laryngoscope 107(4):483-90.

Vahava O, Morell R, Lynch ED, Weiss S, Kagan ME, Ahituv N, Morrow JE, Lee MK, Skvorak AB, Morton CC, Blumenfeld A, Frydman M, Friedman TB, King MC, Avraham KB (1998). Mutation in transcription factor POU4F3 associated with inherited progressive hearing loss in humans. Science 279(5358):1870-1.

Van Den Bogaert K, De Leenheer E M R, Chen W, e col. (2004). A fifth locus for otosclerosis, OTSC5, maps to chromosome 3q22-24. J Med genet 41:450-53.

Van den Ouweland JM, Lemkes HH, Ruitenbeek W, e col. (1992). Mutation in mitochondrial tRNA(Leu)(UUR) gene in a large pedigree with maternally transmitted type II diabetes mellitus and deafness. Nat Geent 1(5):368-71.

Van Camp G, Coucke P, Balemans W, van Velzen D, van de Bilt C, van Laer L, Smith RJ, Fukushima K, Padberg GW, Frants RR, Van de Heyning P, Smith SD, Huizing EH, Willems PJ (1995). Localization of a gene for nonsyndromic hearing loss (DFNA5) to chromosome 7p15. Hum Mol Genet 4:2159-63.

Van Camp G, Coucke P, Willems PJ (1996). Autosomal dominant nonsyndromal hearing loss. In: Martini A, Read A, Stephens D. Genetics and Hearing Impairment. London: 213-220.

Van Camp G, Willems P J, Smith R J H (1997). Nonsydromic Hearing LossUnparalleled Heterogeneity. Am J Hum Genet 60:758-764.

Van Camp G, Smith RJH (03/2012). Hereditary Hearing Loss Homepage. URL: http://webhost.ua.ac.be/hhh/

Van Laer L, McGuirt WT, Yang T, e col. (1999). Autosomal nonsyndromic hearing impairment. Am J Hum Genet 89(3):167-74. Review. 
Verhoeven K, Van Camp G, Govaerts PJ, Balemans W, Schatteman I, Verstreken M, Van Laer L, Smith RJ, Brown MR, Van de Heyning PH, Somers T, Offeciers FE, Willems PJ (1997). A gene for autosomal dominant nonsyndromic hearing loss (DFNA12) maps to chromosome 11q22-24. Am J Hum Genet 60:1168-73.

Verhoeven K, Ensink RJ, Tiranti V, e col (1999). Hearing impairment and neurological dysfunction associated with a mutation in the mitochondrial tRNASer(UCN) gene. Eur J Hum Genet 7(1):45-51.

Verpy E, masmoudi S, Zwaenepodel I, e col. (2001). Mutations in a new gene encoding a protein of the hair bundle cause non-syndromic deafness at the DFNB16 locus. Nat Genet 29:345-9.

Veske A, Oehlmann R, Younus F e col. (1996). Autosomal recessive non-syndromic deafness locus (DFNB8) maps on chromosome 21q22 in a large consanguineous kindred from Pakistan. Hum Mol Genet 5: 164-8.

Vissers LE, de Vries BB, Osoegawa K, e col. (2003) Array-based comparative genomic hybridization for the genome-wide detection of submicroscopic chromosomal abnormalities. Am J Hum Genet 73:1261-1270.

Walenkamp MJE, Karperien M, Pereira AM, e col (2005). Homozygous and Heterozygous Expression of a Novel Insulin-Like Growth Factor-I Mutation. The Journal of Clinical Endocrinology \& Metabolism 90(5):2855-2864.

Walsh TD, Shahin H, Morrow J, e col. (2000). DFNB28, a novel locus for prelingual nonsyndromic autosomal recessive hearing loss maps to $22 \mathrm{q} 13$ in a large consanguineous Palestinian Kindred. $50^{\text {th }}$ Annual Meeting os The American Society of Human Genetics Program Nr: 2059. (http://www.faseb,org/genetics/ashgoo/f2059.htm).

Walsh T, Walsh V, Vreugde S, e col. (2002). From flies' eyes to our ears: Mutations in a human class III myosin cause progressive nonsyndromic hearing loss DFNB30. PNAS 99:7518-7523.

Walsh T, Shahin H, Elkan-Miller T, e col. (2010). Whole exome sequencing and homozygosity mapping identify mutation in the cell polarity protein GPSM2 as the cause of nonsyndromic hearing loss DFNB82. Am J Hum Genet 87(1):90-4.

Wang Y, Treat K, Schroer RJ, e col (1994). Localization of branchio-oto-renal (BOR) syndrome to a $3 \mathrm{Mb}$ region of chromosome 8q. Am. J. Med. Genet. 51: 169175.

Wang QJ, A, Liang Y, Fridell RA, Probst FJ, Wilcox ER, e col. (1998). Association of unconventional myosin MYO15 mutations eith human nonsyndromic deafness DFNB3. Science 280:1447-1451.

Wang QJ, Lu CY, Li N, Rao SQ, Shi YB, Han DY, Li X, Cao JY, Yu LM, Li QZ, Guan MX, Yang WY and Shen Y (2004). Y-linked inheritance of nonsyndromic hearing impairment in a large Chinese family. J Med Genet 41:e80.

Wang QJ, Li QZ, Rao SQ, e col. (2006). AUNX1, a novel locus responsible for X linked recessive auditory and peripheral neuropathy, maps to Xq23-27.3. $J$ Med Genet 43(7):e33. 
Wang Z, Rose DW, Hermanson O, e col (2000). Regulation of somatic growth by the p160 coactivator pyCIP. Proc. Natl. Acad. Sci. USA 10.1073/pnas.260463097.

Wang SH, Wu CC, Lu YC, e col (2012). Mutation Screening of the EYA1, SIX1, and SIX5 Genes in an East Asian Cohort With Branchio-Oto-Renal Syndrome. Laryngoscope, 122:1130-1136.

Warchol ME, Speck JD (2007) Expression of GATA3 and tenascin in the avian vestibular maculae: normative patterns and changes during sensory regeneration. J Comp Neurol 500: 646-657.

Waryah AM, Rehman A, Ahmed ZM, e col. (2009). DFNB74, a novel autosomal recessive nonsyndromic hearing impairment locus on chromosome 12q14.2q15. Clin Genet 76(3):270-5.

Weil D, Kussel P, Blanchard S e col. (1997). The autosomal recessive isolated deafness, DFNB2, and the Usher 1B syndrome are allelic defects of the myosin-VIIA gene. Nat Genet 16: 191-3.

Welch HCE, Coadwell WJ, Ellson CD, e col (2002). P-Rex1, a PtdIns(3,4,5)P3- and G-beta-gamma-regulated guanine-nucleotide exchange factor for Rac. Cell 108: 809-821.

Wilcox SA, Osborn AH, Allen-Powell DR, Maw MA, Dahl H-H M, Gadner RJM (1999). Connexin 26 deafness in several interconnected families. J Med Genet 36: 383-385.

Wilcox ER, Burton QL, Naz S, e col. (2001). Mutations in the gene encoding tight junction claudin-14 cause autosomal recessive deafness DFNB29. Cell 104:165-72.

Willems PJ (2000). Mechanism of Disease: Genetic Causes of Hearing Loss. N Engl J Med 342: 1101-1109.

Wilson CA, Tsuchida MA, Allen GM, e col (2010). Myosin II contributes to cellscale actin network treadmilling through network disassembly. Nature 465:373-377.

Woods KA, Camacho-Hubner C, Savage MO, Clark AJL (1996). Intrauterine growth retardation and postnatal growth failure associated with deletion of the insulinlike growth factor I gene. New Eng J Med 335: 1363-1367.

World

Health

Organization.

URL (http://www.who.int/mediacentre/factsheets/fs300/en/index.html).

Xiao S, Yu C, Chou X, Yuan W, Wang Y, Bu L, Fu G, Qian M, Yang J, Shi Y, Hu L, Han B, Wang Z, Huang W, Liu J, Chen Z, Zhao G, Kong X (2001). Dentinogenesis imperfecta 1 with or without progressive hearing loss is associated with distinct mutations in DSPP. Nat Genet 27:201-4.

Xu J, Liao L, Ning G, e col (2000). The steroid receptor coactivator SRC-3 (p/CIP/RAC3/AIB1/ACTR/TRAM-1) is required for normal growth, puberty, female reproductive function, and mammary gland development. Proc Natl Acad Sci USA (12):6379-84. 
Yan D, Ke X, Blanton SH, e col (2006). A novel locus for autosomal dominant nonsyndromic deafness, DFNA53, maps to chromosome 14q11.2-q12. J Med Genet 43:170-174.

Yang $\mathrm{T} e$ Smith $\mathrm{R}$ (2000). A novel locus DFNA26 maps to chromosome 17q25 in two unrelated families with progressive autosomal dominant hearing loss. 50th Annual Meeting of The American Society of Human Genetics: Program Nr: 1655 (http://www.faseb.org/genetics/ashg00/f1655.htm)

Yariz KO, Duman D, Seco CZ, e col. (2012). Mutations in OTOGL, encoding the inner ear protein otogelin-like, cause moderate sensorineural hearing loss. Am J Hum Genet 91(5):872-82.

Yasunaga S, Grati M, Cohen-Salmon M, e col. (1999). A mutation in OTOF, encoding OTOFerlin, a FER-1-like protein, causes DFNB9, a nonsyndromic form of deafness. Nat Genet 21: 363-9.

Young TL, Ives E, Lynch E, e col (2001). Non-syndromic progressive hearing loss DFNA38 is caused by heterozygous missense mutation in the Wolfram syndrome gene WFS1. Hum Mol Genet 10(22):2509-14.

Zeviani M, Muntoni F, Savarese N, e col. (1993). A MERRF/MELAS overlap syndrome associated with a new point mutation in the mitochondrial DNA tRNA(Lys) gene. Eur J Hum Genet 1(1):80-7.

Zhao H, Li R, Wang Q, e col. (2004). Maternallu inherited aminoglycoside-induced and nonsyndromic deafness is associated with the novel C1494T mutation in the mitochondrial 12S rRNA gene in a large Chinese family. Am J Hum Genet 74(1):139-52.

Zhao Y, Zhao F, Zong L, e col. (2013). Exome Sequencing and Linkage Analysis Identified Tenascin-C (TNC) as a Novel Causative Gene in Nonsyndromic Hearing Loss. PLoS ONE 8(7): e69549. doi:10.1371/journal.pone.0069549.

Zheng J, Miller KK, Yang T, e col. (2011): Carcinoembryonic antigen-related cell adhesion molecule 16 interacts with $\alpha$-tectorin and is mutated in autosomal dominant hearing loss (DFNA4). Proc Natl Acad Sci USA 108:4218-4223.

Zwaenepoel I, Mustapha M, Leibovici M e col. (2002). Otoancorin, an inner ear protein restricted to the interface between the apical surface of sensory epithelia and their overlying acellular gels, is defective in autosomal recessive deafness DFNB22. PNAS 99: 6240-5. 